\title{
Thermodynamic optimisation of the integrated design of a small- scale solar thermal Brayton cycle
}

\author{
W.G. le Roux, T. Bello-Ochende* and J.P. Meyer \\ Department of Mechanical \& Aeronautical Engineering, University of Pretoria, Pretoria \\ 0002, South Africa
}

\begin{abstract}
SUMMARY
The Brayton cycle's heat source does not need to be from combustion but can be extracted from solar energy. When a black cavity receiver is mounted at the focus of a parabolic dish concentrator, the reflected light is absorbed and converted into a heat source. The second law of thermodynamics and entropy generation minimisation are applied to optimise the geometries of the recuperator and receiver. The irreversibilities in the recuperative solar thermal Brayton cycle are mainly due to heat transfer across a finite temperature difference and fluid friction. In a small-scale open and direct solar thermal Brayton cycle with a micro-turbine operating at its highest compressor efficiency, the geometries of a cavity receiver and counterflow-plated recuperator can be optimised in such a way that the system produces maximum net power output. A modified cavity receiver is used in the analysis, and parabolic dish concentrator diameters of six to 18 metres are considered. Two cavity construction methods are compared. Results show that the maximum thermal efficiency of the system is a function of the solar concentrator diameter and choice of micro-turbine. The optimum receiver tube diameter is relatively large when compared with the receiver size. The optimum recuperator channel aspect ratio for the highest maximum net power output of a micro-turbine is a linear function of the system mass flow rate for a constant recuperator height. For a system operating at a relatively small mass flow rate, with a specific concentrator size, the optimum recuperator length is small. For the systems with the highest maximum net power output, the irreversibilities are spread throughout the system in such a way that the internal irreversibility rate is almost three times the external irreversibility rate.
\end{abstract}

KEYWORDS: Brayton; solar; entropy; minimisation; receiver; recuperator

\section{INTRODUCTION}

A heat source can be considered as the Brayton cycle's life support. This heat source does not need to be from combustion, which is mostly the case, but can be extracted from solar energy. The major advantage of Brayton cycle engines is its potential for low operation and maintenance cost and these engines are therefore considered for both small-scale and large-scale power applications. The highest-efficiency Brayton cycles are regenerative cycles with low pressure ratios. The Brayton cycle is definitely worth studying when

*Correspondence to: T. Bello-Ochende, Department of Mechanical and Aeronautical Engineering, University of Pretoria, Pretoria 0002, South Africa, E-mail address:

tunde.bello-ochende@up.ac.za 
comparing its efficiency with those of other power cycles [1]. Emphasis may shortly shift to solarised Brayton micro-turbines from Dish-Stirling technology due to high Stirling engine costs [2]. Shah [3] regards the Honeywell turbomachinery as worth mentioning when it comes to their development expertise in micro-turbines in recent history. It is suggested [3] that a counterflow thin foil primary surface recuperator (same surface on both fluid sides) should be used as a compact micro-turbine recuperator. Counterflow heat exchangers find numerous applications in regenerative heating associated with advanced gas power cycles [4], and should be used in solar thermal application [5].

The irreversibilities of the solar thermal Brayton cycle are due to heat transfer across a non-zero temperature difference and fluid friction. These irreversibilities tend to compete with one another when a thermodynamic optimum is required [4, 6, 7]. For heat exchangers, it is important to take the losses due to heat exchange to the environment into consideration [8]. Second-law aspects of heat exchanger performance and proposed ways of reducing irreversibility production are available [4]. The irreversibility in a heat exchanger is the sum of the associated irreversibilities of each of the two surfaces of the heat exchanger, and the irreversibility of a fixed area heat exchanger can be reduced by properly distributing (arranging) the area $[4,6]$. For a solar receiver configuration, Bejan [4] mentions three main features that cause thermodynamic irreversibilities in its operation: sun receiver heat exchange, receiver ambient heat loss and the internal irreversibility in the receiver. A solar receiver can be viewed as a blackbody that is exposed to blackbody radiation of a higher temperature, and an optimal receiver temperature for maximum power per unit area can be determined in three ways: by maximising the net power output, minimising the entropy generation rate, or by maximising the exergy streaming [9].

According to the Gouy-Stodola theorem, the maximisation of exergy output in a solar thermal system is identical to the minimisation of total entropy generation in the system, between the apparent sun temperature as an exergy source $\left(T^{*}\right)$ and the environment temperature $\left(T_{0}\right)$ [4, 6, 9]. The entropy generation rate involved with the transformation of monochromatic radiation into blackbody radiation and scattering is available [9].

The exact exergy of solar radiation depends on direct and diluted radiation components, the time of day, season of the year, geographic location, and local weather and landscape. It could be determined with spectral measurement and calculation according to Petela [10]. The concept of solar exergy maps has also been developed [11]. A collection and interrelation of the fundamental concepts about the second-law analysis of thermal radiation are available [12].

A black solar receiver, mounted at the focus of a parabolic dish concentrator can be sized such that it absorbs the maximum amount of heat [13]. Convection losses can be drastically reduced by employing a receiver mounted in a cavity and a selective coating for reducing the thermal losses due to radiation. Different classical cavity geometries were investigated and it was found that the cavity geometry has a significant effect on the overall heat flux distribution [14]. Heat losses from a solar cavity receiver at different inclination angles and head-on and side-on winds were investigated and it was found that the thermal and optical losses occurring from an open-cavity solar receiver were less when compared with other types of receivers [15]. Sendhil Kumar and Reddy [16] compared different types of cavity receivers numerically and found that their modified 
cavity receiver experiences lower convection heat losses than the other receivers and suggested that it may be preferred in a solar dish collector system. For this modified cavity receiver, a numerical investigation of natural convection heat loss is available [17], the contribution of radiation losses is considered [18] and an improved model for natural convection heat loss is available [19].

Entropy generation minimisation (EGM) has been used in various internal flow optimisation studies such as: the optimum tube diameter or Reynolds number for a tube $[4,6]$; the optimal Reynolds number for single-phase, fully developed, laminar and turbulent flow with constant heat flux [20]; and the optimum channel geometries with constant wall temperature or constant heat flux [21-23]. A rectangular channel with aspect ratio of eight, gives the minimum entropy generation in laminar flow and turbulent flow according to Ratts and Raut [20]. Entropy generation and its minimisation have also been expressed for numerous heat exchangers and heat transfer surfaces: counterflow and nearly ideal heat exchanger neglecting fluid friction [24], tubular heat exchangers [25, 26], heat exchangers restricted to perfect gas flows [27], balanced cross-flow recuperative plate-type heat exchangers with unmixed fluids [7]; and a parallel-plate ideal gas counterflow heat exchanger [28]. The $\varepsilon-N T U$ method, based on the second law of thermodynamics, can be used to get the outlet temperatures and the total heat transfer from the hot fluid to the cold fluid [7, 27, 28]. Heat exchanger optimisation using EGM has been utilised in various applications: a thermoacoustic engine [29]; a condenser in a vapour-compression cycle refrigeration system for environmental control of aircraft [30]; and cryogenics [31].

A thermodynamic analysis and optimisation of a subcritical Rankine cycle using a finite low-temperature heat source are available [32]. Exergetic analysis in solar thermal application has been respectively done for a solar thermal Rankine heat engine [33] and a regenerative Brayton cycle with isothermal heat addition and isentropic compressor and turbine [34]. In an exergy analysis for a nuclear plant [35], the minimisation of exergy destruction is identified as the optimisation criterion. In the thermodynamic optimisation of a solar system for cogeneration of water heating and absorption cooling [36], a system global optimisation for maximum performance (or minimum exergy destruction) is performed. Using the steam-injected gas turbine plant as example, it is claimed that higher efficiencies of combined cycles can be attained with thermodynamic optimisation [37]. It was shown that the topology of a heat transfer installation can be deduced by maximising the global performance of the system that employs it [38].

Various authors have emphasised the importance of the optimisation of the global performance of a system, by minimising the sum of the irreversibilities from all the different components or processes of the system (spreading the entropy generation rate through the system by optimally sizing the hardware, instead of optimising components individually) $[6,9,21,23,28,30,39]$. For the open and direct solar thermal Brayton cycle, an optimisation of this kind is not available from the literature. The geometries of the modified cavity receiver and counterflow plate-type recuperator can be optimised for maximum net system power output, by minimising the total entropy generation rate in this solar thermal power system.

\section{PHYSICAL AND MATHEMATICAL MODEL}


The open and direct solar thermal Brayton cycle is shown in Figure 1. A parabolic concentrator supplies solar heat at the cavity receiver. The geometry of the receiver and recuperator can be optimally sized, such that the system produces maximum net power output $\left(\dot{W}_{n e t}\right)$. Take note that the authors are not concerned with determining the precise amount of power available for utilisation at the receiver (methods for determining the exact exergy of solar radiation are available [10-12]), but the authors are concerned with determining the optimum utilisation of the available power at the receiver, with an optimum design.

\subsection{The control volume}

In Figure $1, \dot{Q}^{*}$ is the power intercepted by the cavity receiver aperture from the available power for utilisation. The available power for utilisation depends on the specific location and time. A steady-state model is used and therefore the available power for utilisation is constant. Most areas in South Africa receive an average of more than 2500 hours of sunshine per year, with average solar radiation levels ranging between 4.5 and $6.5 \mathrm{kWh} / \mathrm{m}^{2}$ per day [40]. The irradiance for the model is assumed to be $1000 \mathrm{~W} / \mathrm{m}^{2} . \dot{Q}^{*}$ depends on the cavity receiver aperture (the cavity receiver design). $\dot{Q}^{*}$ would thus be the intercepted power at the receiver, after the irreversibility rates due to scattering and the transformation of radiation had been deducted. For the analysis in this work, $T^{*}$ is assumed to be at a point between the concentrator and receiver. The concentrator specular reflectance is assumed to be 0.93 .

\subsection{Solar receiver model}

The solar collector consists of a parabolic concentrator and modified cavity receiver proposed by Reddy and Sendhil Kumar [19]. The convection heat loss takes place through the receiver aperture. The receiver diameter, $D$, is a multiple of the aperture diameter of the receiver, $d$. In this analysis, this multiple is fixed. An area ratio of $A_{w} / A_{a}=8$ is recommended [19] as it was found to be the ratio that gives the minimum heat loss from the cavity receiver. Since the surface area of a sphere is $\pi D^{2}$, it is assumed that the diameter of the receiver can be calculated as

$$
D=2 \sqrt{\left(A_{w}+A_{a}\right) / 3 \pi}
$$

By taking into consideration the recommended area ratio of $A_{w} / A_{a}=8$, for minimum heat loss, the receiver diameter can be determined as a function of the receiver aperture diameter (Figure 2a),

$$
D=\sqrt{3} d
$$

The receiver inner surface is made up of a closely wound copper tube with diameter, $D_{\text {rec }}$ - this wound tube forms a continuous hemispherical surface [19]. The working fluid is 
pumped concentrically through the wound tube, as shown in Figure 2a. This tube, with tube diameter, $D_{r e c}$, and tube length, $L_{r e c}$, constructs the cavity receiver and its aperture these are the geometric variables to be optimised for the receiver. The receiver aperture diameter can be calculated using Equation (3) since $A_{w}=D_{r e c} L_{r e c}$.

$d=\sqrt{D_{r e c} L_{r e c} / 2 \pi}$

Another method would be to use a rectangular channel (Figure 2b). Both of these methods are used in this paper and the results are compared. For a rectangular channel, the hydraulic tube diameter, $D_{h, r e c}$, tube length, $L_{r e c}$, and aspect ratio $(a / b)_{r e c}$ construct the cavity receiver and its aperture. The longer side of the channel, $a$, can be described with Equation (4) as a function of the channel aspect ratio,

$a=D_{h, r e c}\left((a / b)_{r e c}+1\right) / 2$

The receiver aperture diameter is given by Equation (5), since $A_{w}=a L_{r e c}$.

$d=\sqrt{D_{h, r e c} L_{r e c}\left((a / b)_{r e c}+1\right) / 4 \pi}$

For $A_{w} / A_{a}=8$ and a $0^{\circ}$ tilt angle (vertical aperture plane), the ratio of the contribution of radiation to convection heat loss is $47: 52$. This ratio shifts to $57: 43$ when the tilt angle is $90^{\circ}$ [18]. It is therefore assumed that $\dot{Q}_{\text {loss-rad }} \approx \dot{Q}_{\text {loss-conv }}$ or $\dot{Q}_{\text {loss }} \approx 2 \dot{Q}_{\text {loss-conv }}$ for the modified cavity receiver. According to Reddy and Sendhil Kumar [19], for $A_{w} / A_{a}=8$, the Nusselt number for natural convection heat loss based on receiver diameter for a 3-D receiver model can be calculated as a function of the inclination angle of the receiver,

$$
N u_{D}=h_{\text {conv }} D / k=0.698 G r_{D}^{0.209}(1+\cos \beta)^{0.968}\left(T_{w} / T_{0}\right)^{-0.317}(d / D)^{0.425}
$$

The total rate of heat loss due to convection and radiation can therefore be approximated as

$$
\dot{Q}_{\text {loss }} \approx 1.396 G r_{D}^{0.209}(1+\cos \beta)^{0.968}\left(T_{w} / T_{0}\right)^{-0.317}(d / D)^{0.425}\left(k A_{a} / D\right)\left(T_{w}-T_{0}\right)
$$

Heat loss through conduction at the cavity receiver through the insulation is usually small. It is assumed that the rate of conduction heat loss is $10 \%$ of the sum of the radiation and convection heat loss rates.

\subsection{Determination of net absorbed power}

For a specific concentrator diameter (with constant focal length and rim angle), the net rate of heat absorbed by the working fluid in the receiver depends on the receiver aperture diameter. The sun's rays are not truly parallel and concentrator errors exist, which means that the reflected rays form an image of finite size centred about the focus, 
instead of a focal point. The larger the aperture diameter, the larger the rate of heat intercepted by the receiver, $\dot{Q}^{*}$. Also, the larger the aperture diameter, the larger the heat loss rate, $\dot{Q}_{\text {loss }}$, due to convection and radiation (Equation (7)). The net rate of absorbed heat, $\dot{Q}_{n e t}$, is the intercepted heat rate minus the total heat loss rate. $\dot{Q}_{n e t}$ is a function of the cavity aperture diameter, $d$, which is a function of the geometry variables of the receiver. The sizing algorithm of Stine and Harrigan [13] is applied to determine $\dot{Q}^{*}$ for a specific aperture diameter. Starting at a rim angle of $0^{\circ}$ through to an angle of $\psi_{\text {rim }}$, in increments of $1^{\circ}$, the amount of intercepted solar power per segment of concentrator area is computed using a flux capture fraction with standard deviations of the total angular error. The power from each segment is added to get $\dot{Q}^{*}$. The shadow of the receiver and its insulation is also accounted for when calculating the intercepted power. Figure 3 shows the relation between $\dot{Q}_{n e t}$ and the receiver aperture diameter for a number of different concentrator diameters and a parabolic concentrator error of $6.7 \mathrm{mrad}$, as suggested by Stine and Harrigan [13]. From this curve, one can see that for a specific concentrator size an aperture diameter exists, which gives the maximum $\dot{Q}_{n e t}$. This curve can be numerically approximated with the discrete least-squares approximation method [41], where $y_{i}$ is a set of constants used to describe the function,

$\dot{Q}_{n e t}=\sum_{i=0}^{10} y_{i} d^{i}$

Different concentrator sizes $\left(6-18 \mathrm{~m}\right.$ diameter) and $45^{\circ}$ rim angle (maximum concentration ratio for a parabolic dish and cavity receiver configuration prescribed by Stine and Harrigan [13]) are used. The receiver inclination is $90^{\circ}$ (receiver aperture lies in the horisontal plane).

\subsection{Recuperator model}

A counterflow plate-type recuperator is used and the design and assembly are illustrated in Figure 4, where plates are stacked to create flow channels. The geometry variables for the recuperator to be optimised are the channel hydraulic diameter, $D_{h, \text { reg }}$, tube length, $L_{r e g}$, and aspect ratio, $a / b_{r e g}$. The recuperator efficiency can be calculated using the $\varepsilon-N T U$ method. The number of flow channels in the recuperator, $n$, depends on the recuperator height, $H$, channel height, $b$, and thickness of the channel separating surface, $t$, and can be written as a function of the channel aspect ratio,

$$
n=H /(t+b)=\frac{H}{t+D_{h, \text { reg }}\left((a / b)_{\text {reg }}+1\right) /\left(2(a / b)_{\text {reg }}\right)}
$$

Equation (10) gives the mass flow rate per channel.

$\dot{m}_{c}=2 \dot{m} / n$ 
The surface area, $A_{s}$, for a channel as a function of the channel aspect ratio is

$$
A_{s}=2(a+b) L_{r e g}=D_{h, r e g} L_{r e g}\left((a / b)_{r e g}+1\right)\left(1+(a / b)_{r e g}^{-1}\right)
$$

The Reynolds number for a flow channel is

$$
\operatorname{Re}=\dot{m}_{c} D_{h, r e g}(a / b)_{r e g} / \mu a^{2}
$$

Using Equation (4) and Equation (12), the Reynolds number can be calculated with

$$
\operatorname{Re}=\frac{4(a / b)_{r e g} \dot{m}_{c}}{\mu D_{h, r e g}\left((a / b)_{r e g}+1\right)^{2}}
$$

Heat exchanger irreversibilities can be reduced by slowing down the movement of fluid through a heat exchanger [4]. Small Reynolds numbers can thus be expected for the optimised recuperator channels, and the Gnielinski equation [42] can be used to determine the Nusselt number,

$$
N u_{D}=(\operatorname{Pr}(\operatorname{Re}-1000)(f / 8)) /\left(1+12.7(f / 8)^{0.5}\left(\operatorname{Pr}^{2 / 3}-1\right)\right)
$$

The Petukhov equation (Equation (15)) [43] is used to calculate the friction factor,

$$
f=(0.79 \ln \operatorname{Re}-1.64)^{-2}
$$

With the use of the friction factor, and the definition of the pressure drop, the pressure drop through the recuperator can be written in terms of the geometric variables as

$$
\Delta P=\left(0.79 \ln \frac{4 \dot{m}_{c}(a / b)_{r e g}}{\mu D_{h, r e g}\left(a / b_{r e g}+1\right)^{2}}-1.64\right)^{-2}\left(\frac{8 \dot{m}_{c}^{2}(a / b)_{r e g}^{2}}{\rho\left(a / b_{r e g}+1\right)^{4}}\right)\left(L_{r e g} / D_{h, r e g}{ }^{5}\right)
$$

For the recuperator, the following assumptions are made: the thickness of the material between the hot and cold stream is constant at $1 \mathrm{~mm}$; copper is used as material with thermal conductivity of $k_{\text {solid }}=401 \mathrm{~W} / \mathrm{mK}$; the height of the recuperator is constant at $1 \mathrm{~m}$. The recuperator efficiency is calculated using the $\varepsilon-N T U$ method with the fouling factor for air given as $R_{f}=0.004$ [44].

\subsection{Compressor and turbine properties}

Forty-five (45) standard micro-turbines are used in the analysis. The compressor pressure ratio $\left(r=P_{2} / P_{1}\right)$ should be chosen to be a parameter when considering geometric optimisation [45]. The mass flow rate through the system depends on the compressor, 
which, in turn, depends on the turbine of the micro-turbine. The compressor efficiency, mass flow rate and compressor pressure ratio are intrinsically coupled to each other, when considering standard micro-turbines from Honeywell [46]. The compressor pressure ratio as a parameter fixes the mass flow rate and compressor efficiency as parameters. The highest compressor efficiency is on the island in the middle of a compressor map (between two mass flow rate values: $\dot{m}_{l o w}$ and $\dot{m}_{\text {high }}$, and between two pressure ratio values: $r_{\text {low }}$ and $\left.r_{\text {high }}\right)$. Different operating points on the island of maximum compressor efficiency of a micro-turbine can be considered with the straight-line approximation of

$$
\dot{m}=\frac{\left(\dot{m}_{\text {high }}-\dot{m}_{\text {low }}\right)}{\left(r_{\text {high }}-r_{\text {low }}\right)}\left(r-r_{\text {low }}\right)+\dot{m}_{\text {low }}
$$

An optimum operating condition for a specific micro-turbine exists, which would (with its optimised geometry) give the highest maximum net power output for the system. The operating conditions are used as parameters in the objective function. The maximum of the objective function can be found at different parameter values.

\subsection{The objective function}

The objective function is the function which is maximised by the optimisation of variables. The net power output of the system should be written in terms of the total entropy generation rate in the system. In this section, the entropy generation mechanisms are identified and the objective function is constructed.

\subsubsection{Construction of the objective function}

When doing an exergy analysis for the system and assuming $V_{1}=V_{11}$ and $Z_{1}=Z_{11}$, the objective function can be assembled as given in Equation (18). The function to be

maximised (the objective function), is $\dot{W}_{n e t}$ (the net power output). Equation (19) shows the total entropy generation rate in terms of the temperatures and pressures (with reference to Figure 1). The entropy generation rate due to each component is added. Note that each temperature and pressure shown below can be written in terms of the geometry variables as will be explained in the next section.

$$
\dot{W}_{n e t}=-T_{0} \dot{S}_{g e n}+\left(1-\frac{T_{0}}{T^{*}}\right) \dot{Q} *+\dot{m} c_{p 0}\left(T_{1}-T_{11}\right)-\dot{m} T_{0} c_{p 0} \ln \left(T_{1} / T_{11}\right)
$$

where

$$
\begin{aligned}
& \dot{S}_{g e n}=\left\lfloor-\dot{m} c_{p 0} \ln \left(T_{1} / T_{2}\right)+\dot{m} R \ln \left(P_{1} / P_{2}\right)\right\rfloor_{\text {compressor }} \\
& +\left[\dot{Q}_{0} / T_{0}+\dot{m} c_{p 0} \ln \left(T_{3} / T_{2}\right)-\dot{m} R \ln \left(P_{3} / P_{2}\right)\right\rfloor_{\text {Duct } 23}
\end{aligned}
$$




$$
\begin{aligned}
& +\left[\dot{m} c_{p 0} \ln \left[\frac{T_{10} T_{4}}{T_{9} T_{3}}\left(\frac{P_{10} P_{4}}{P_{9} P_{3}}\right)^{(1-k) / k}\right]+\dot{Q}_{0} / T_{0}\right]_{\text {recuperator }} \\
& +\left[\dot{Q}_{0} / T_{0}+\dot{m} c_{p 0} \ln \left(T_{5} / T_{4}\right)-\dot{m} R \ln \left(P_{5} / P_{4}\right)\right]_{\text {Duct } 45} \\
& +\left[-\frac{\dot{Q}^{*}}{T^{*}}+\frac{\dot{Q}_{\text {loss }}}{T_{0}}+\dot{m} c_{p 0} \ln \left(T_{6} / T_{5}\right)-\dot{m} R \ln \left(P_{6} / P_{5}\right)\right]_{\text {receiver }} \\
& +\left[\dot{Q}_{0} / T_{0}+\dot{m} c_{p 0} \ln \left(T_{7} / T_{6}\right)-\dot{m} R \ln \left(P_{7} / P_{6}\right)\right]_{\text {Duct } 67} \\
& +\left[-\dot{m} c_{p 0} \ln \left(T_{7} / T_{8}\right)+\dot{m} R \ln \left(P_{7} / P_{8}\right)\right]_{\text {turbine }} \\
& +\left[\dot{Q}_{0} / T_{0}+\dot{m} c_{p 0} \ln \left(T_{9} / T_{8}\right)-\dot{m} R \ln \left(P_{9} / P_{8}\right)\right]_{\text {Duct } 89}
\end{aligned}
$$

Also note that $\dot{Q}^{*}-\dot{Q}_{\text {loss }}=\dot{Q}_{n e t}$.

\subsubsection{Temperatures and pressures in terms of geometry variables}

The temperatures and pressures in Equations (18) and (19) can be written in terms of geometric variables. This is done with the use of iteration and in five phases. Consider firstly, a cavity receiver constructed with a tube (Figure 2a). The first iteration phase uses $T_{1}=300 \mathrm{~K}$, the compressor pressure ratio and the compressor efficiency to get $T_{2} . T_{3}$ is calculated by assuming a small constant temperature loss in the duct. The second phase uses the guess of $T_{5}=800 \mathrm{~K} . T_{6}$ is calculated with Equations (3) and (8), which describes the net rate of absorbed heat in terms of the geometry variables.

$T_{6}=\frac{\sum_{i=0}^{10} y_{i}{\sqrt{D_{r e c} L_{r e c} / 2 \pi}}^{i}}{\dot{m} c_{p}}+T_{5}$

$T_{7}$ is calculated with an assumption of the duct temperature loss. The third phase consists of calculating the pressures. Note that $P_{3}, P_{5}, P_{7}$ and $P_{8}$ are calculated with an assumed pressure loss for the duct. $P_{1}$ is chosen conservatively as $80 \mathrm{kPa}$ and $P_{4}, P_{6}$ and $P_{9}$ are calculated using Equations (21) - (23). These equations describe the pressure drop in the flow channels in terms of the geometric variables and are shown below

$$
\begin{aligned}
& P_{4}=P_{3}-\left(0.79 \ln \frac{4 \dot{m}_{c}(a / b)_{r e g}}{\mu D_{h, r e g}\left((a / b)_{r e g}+1\right)^{2}}-1.64\right)^{-2}\left(\frac{8 \dot{m}_{c}^{2}(a / b)_{r e g}^{2}}{\rho\left((a / b)_{r e g}+1\right)^{4}}\right)\left(\frac{L_{r e g}}{D_{h, r e g}{ }^{5}}\right) \\
& P_{6}=P_{5}-\left(0.79 \ln \frac{4 \dot{m}}{\mu \pi D_{\text {rec }}}-1.64\right)^{-2}\left(\frac{8 \dot{m}^{2}}{\rho \pi^{2}}\right)\left(\frac{L_{r e c}}{D_{r e c}^{5}}\right)
\end{aligned}
$$




$$
P_{9}=P_{10}+\left(0.79 \ln \frac{4 \dot{m}_{c}(a / b)_{\text {reg }}}{\mu D_{h, \text { reg }}\left((a / b)_{\text {reg }}+1\right)^{2}}-1.64\right)^{-2}\left(\frac{8 \dot{m}_{c}^{2}(a / b)_{\text {reg }}^{2}}{\rho\left((a / b)_{r e g}+1\right)^{4}}\right)\left(\frac{L_{r e g}}{D_{h, r e g}{ }^{5}}\right)
$$

In the fourth phase, Equation (24) is used to determine $T_{8}$ in conjunction with the turbine efficiency. $T_{9}$ is calculated with the assumption of a temperature loss in the duct. $T_{10}$ is calculated with the efficiency of the recuperator (Equation (25)). The last phase calculates $T_{5}$ using an assumption of the temperature loss in the duct and $T_{4}$ is calculated with the recuperator efficiency (Equation (26)). $T_{5}$ is then used as the new approximation for $T_{5}$ in Phase 1. This iteration continues until the error is smaller than 0.001. These temperature and pressure values are then used to determine the objective function (Equations (18) and (19)).

$$
\begin{aligned}
& T_{8}=T_{7}\left[1-\eta_{t}\left[1-\frac{1}{\left(P_{7} / P_{8}\right)^{(k-1) / k}}\right]\right] \\
& T_{11}=T_{10}=T_{9}-\eta_{\text {reg }}\left(T_{9}-T_{3}\right) \\
& T_{4}=T_{3}+\eta_{\text {reg }}\left(T_{9}-T_{3}\right)
\end{aligned}
$$

When the cavity receiver is constructed with a rectangular channel, the following equations are used for the receiver exit temperature and pressure respectively,

$$
\begin{aligned}
& T_{6}=\frac{\sum_{i=0}^{10} y_{i}{\sqrt{D_{h, r e c} L_{r e c}\left((a / b)_{r e c}+1\right) / 4 \pi}}^{i}}{\dot{m} c_{p}}+T_{5} \\
& P_{6}=P_{5}-\left(0.79 \ln \frac{4 \dot{m}(a / b)_{\text {rec }}}{\mu D_{h, \text { rec }}\left((a / b)_{\text {rec }}+1\right)^{2}}-1.64\right)^{-2}\left(\frac{8 \dot{m}^{2}(a / b)_{\text {rec }}{ }^{2}}{\rho\left((a / b)_{\text {rec }}+1\right)^{4}}\right)\left(\frac{L_{\text {rec }}}{D_{h, \text { rec }}{ }^{5}}\right)
\end{aligned}
$$

\subsubsection{Constraints}

Now, consider the rectangular channel receiver. For the concentration ratio constraint of $C R \geq 100$, we obtain Equation (29). The width of the rectangular channel, $a$, in the receiver, cannot be larger than the distance between the aperture and the edge of the receiver (Equation (30)). Equation (31) results from Equation (30) when including Equation (4). For a tube receiver, the same equations can be used, but with $(a / b)_{\text {rec }}=1$.

$$
\begin{aligned}
& D_{h, r e c} L_{r e c}\left((a / b)_{r e c}+1\right) / 16-A_{\text {conc }} / 100<0 \\
& (\sqrt{3}-1) d / 2 \geq a
\end{aligned}
$$




$$
D_{h, \text { rec }}\left((a / b)_{\text {rec }}+1\right) / 2-((\sqrt{3}-1) / 2) \sqrt{D_{h, \text { rec }} L_{\text {rec }}\left((a / b)_{\text {rec }}+1\right) / 4 \pi} \leq 0
$$

Equation (32) prevents the receiver from losing its cavity shape, by only allowing a minimum of two tube diameters in the distance between the aperture edge and the edge of the receiver, when a tube receiver is used.

$$
2 D_{\text {rec }}-((\sqrt{3}-1) / 2) \sqrt{D_{\text {rec }} L_{\text {rec }} / 2 \pi} \leq 0
$$

The surface temperature of the receiver (of copper) should stay well below its melting temperature and below the maximum inlet temperature of the micro-turbines (more or less $1220 \mathrm{~K}$ or $1320 \mathrm{~K}$ intermittently) [3, 46]. A maximum temperature of $1200 \mathrm{~K}$ is chosen.

The surface area of a channel (Equation (33) for rectangular channel), with the Dittus-Boelter equation [47], helps us to construct Equations (34a) and (34b). These are the maximum surface temperatures of the receiver for the cases where rectangular channel and round tube configurations are used respectively.

$$
A_{s}=D_{h, r e c} L_{r e c}\left((a / b)_{r e c}+1\right)\left(1+(a / b)_{\text {rec }}^{-1}\right)
$$

Plate :

$$
T_{s}=T_{6}+\frac{\dot{Q}_{\text {net }}}{0.023 L_{\text {rec }}\left((a / b)_{\text {rec }}+1\right)\left(1+(a / b)_{\text {rec }}^{-1}\right) k \operatorname{Pr}^{0.4}\left(\frac{4 \dot{m}(a / b)_{\text {rec }}}{\mu D_{h, \text { rec }}\left((a / b)_{\text {rec }}+1\right)^{2}}\right)^{0.8}}
$$

Tube:

$T_{s}=T_{6}+\frac{\dot{Q}_{\text {net }}}{0.023 \pi L_{\text {rec }} k \operatorname{Pr}^{0.4}\left(4 \dot{m} /\left(\mu \pi D_{\text {rec }}\right)\right)^{0.8}}$

The longer the recuperator, the more beneficial it is to the system from a heat transfer standpoint. There needs to be a constraint on the recuperator's length to keep the length within a realistic region. In this analysis, the recuperator's length is constrained to the radius of the dish concentrator (Equation (35)) so that the system with recuperator stays compact. When the receiver walls are constructed using a rectangular channel, the channel should have an aspect ratio equal to or larger than 2.5 , to ensure that the shape of the cavity receiver is maintained (Equation (36)).

$L_{\text {reg }} \leq D_{\text {conc }} / 2$

$2.5-(a / b)_{r e c} \leq 0$ 


\section{GEOMETRICAL OPTIMISATION}

There are six geometric variables (six degrees of freedom) to be optimised: The hydraulic diameter of the cavity receiver tube or channel, $D_{h \text {,rec }}$, the tube or channel length of the cavity receiver, $L_{r e c}$, aspect ratio of the cavity receiver channel, $(a / b)_{\text {rec }}$, (where $(a / b)_{r e c}=1$ for a tube), the hydraulic diameter of the recuperator channels, $D_{h, r e g}$, the length of the recuperator channels, $L_{r e g}$, and aspect ratio of the recuperator channels, $(a / b)_{\text {reg. }}$.

The objective function (net power output of the system) in terms of the scaled geometry variables, parameters and constants is maximised using the dynamic trajectory optimisation method for constrained optimisation [48] in MATLAB, with unit step size and convergence tolerance of 1E-7. The optimisation algorithm, LFOPC [48], requires the gradient of the objective function in each variable. Because of the iteration involved with the objective function, the differential in a certain variable is difficult to obtain. The gradient of the function for each of the variables in vector $X$, can be obtained by taking a small increment, $h=1 \mathrm{E}-8$, positive and negative of the variable value, to get two function values. The slope can then be calculated at the specific point in space.

Optimisation of the geometry variables was done by maximising the objective function at different parameters, which include: a range of parabolic dish diameters, a range of micro-turbines [46] and a range of compressor pressure ratios (along the line of highest compressor efficiency on the compressor map of a specific micro-turbine).

\section{RESULTS AND DISCUSSION}

The analysis found the optimum geometry variables which produce maximum net power output for the system for the different parameters. These parameters are the concentrator diameter, micro-turbine used and micro-turbine operating conditions.

Figure 5 shows the maximum net power output, minimum internal and external irreversibility rates and maximum net absorbed heat rate for different operating conditions of Micro-turbine 41 with a concentrator diameter of $14 \mathrm{~m}$. The maximum net power output of the system at each operating condition (mass flow rate), was found by optimising the geometry variables to maximise the objective function. One can see that the highest (global) maximum net power output and the lowest minimum irreversibility or minimum entropy generation (global) rates are at the same operating point. This result is in agreement with the second law of thermodynamics, that the point of global minimum irreversibility corresponds to the point of global maximum net power output for a set of given mass flow rates.

Figure 6 shows the maximum net power output of different micro-turbines as a function of the mass flow rate, for a concentrator with a $14 \mathrm{~m}$ diameter as an example. Note that each of these data points in the operating range of each micro-turbine, has a maximum net power output and optimum geometry as was determined with the optimisation algorithm. Furthermore, for each micro-turbine, there exists a specific operating condition which gives the highest maximum net power output.

The thermal efficiencies of the data points with highest maximum net power output are shown in Figure 7 at different concentrator diameters and micro-turbines. The 
thermal efficiency is a function of the concentrator diameter and micro-turbine used. A higher thermal efficiency can be expected when using a larger concentrator, although, an even higher thermal efficiency can result when using a specific micro-turbine.

In some cases, a single micro-turbine had an optimum operating condition (or point of highest maximum net power output) for a number of different concentrator diameters. Figure 8 shows that for a specific micro-turbine (Number 41 in this example), there exists a line of maximum net power output as a function of mass flow rate. The larger the concentrator, the more the net power output tends towards this line. The smaller the concentrator diameter, and the higher the mass flow rate, the lower maximum net power output can be expected. Thus, for a specific micro-turbine, the larger the concentrator diameter, the larger the mass flow rate should be to attain the highest maximum net power output.

The results were found for each of the two receiver construction methods (circular tube or rectangular channel) and they were compared. No significant difference could be found in the maximum net power output, but each receiver construction method had its own optimum geometry.

For the optimised rectangular channel receiver, most of the results were found on the limit of one of two constraints. These constraints are for $C R \geq 100$ and $(a / b)_{\text {rec }} \geq 2.5$. A large cavity aperture or small aspect ratio for the rectangular channel, but not necessarily both, is beneficial. When considering the tube receiver, it is interesting to note that most of these optima also lie on the aperture size constraint of $C R=100$. It can be concluded that it is beneficial for the system's net power output, that the receiver aperture is relatively large in comparison with the concentrator diameter. This can be expected since only natural convection heat loss from the receiver (no wind) is modelled. It was also found that the receiver of the optimised system would not necessarily have the aperture diameter that intercepts the maximum solar heat input as shown in Figure 3, due to the constraints.

From each of the optimised data in the analysis, it was found that there exists an optimum number of tube diameters, $N_{D}$, or rectangular channels, $N_{R}$, that fit in between the receiver aperture edge and the receiver edge (in Figure $2 \mathrm{a}$, for example, $N_{D}=4$ ). The definition of $N_{D}$ is shown in Equation (37).

$N_{D}=((\sqrt{3}-1) d) /\left(2 D_{r e c}\right)$

For a specific concentrator diameter and at large mass flow rates, $N_{D}$ decreases as the mass flow rate increases until it reaches its constraint of two. It was found that for all the data points in the analysis, $2 \leq N_{D} \leq 4$. This means that the optimum receiver tube diameter is mostly relatively large. For the receiver constructed with rectangular channel, $D_{\text {rec }}$ in Equation (37), can be replaced with $a$ - the longest side of the rectangular channel. For all the optimised receiver rectangular channels in the analysis, it was found that $1 \leq N_{R} \leq 2.3$. Figure 9 shows that for optimum receiver channel geometry in all of the concentrator and micro-turbine combinations, a large aspect ratio is accompanied with a small $N_{R}$ and a large $N_{R}$ is accompanied with a small aspect ratio.

For the receiver constructed with circular tube, there exists a relationship between the optimum receiver diameter $D_{\text {rec,opt }}$ and the optimum receiver length $L_{\text {rec,opt }}$. This is 
shown in Figure 10. It is optimum for a long receiver tube to have a small tube diameter and vice versa, except at very small receiver tube lengths where the tube diameter is also small. For the receiver constructed with a rectangular channel, however, there is no established relationship between the optimum hydraulic diameter and optimum channel length. This can be expected because the optimum hydraulic diameter of a rectangular channel is a function of the optimum channel aspect ratio.

When plotting the optimum recuperator channel aspect ratio, $(a / b)_{\text {reg,opt, as a }}$ function of the system mass flow rate, Figure 11 arises. A linear relationship is produced, which can be approximated with Equation (38).

$(a / b)_{\text {reg,opt }} \approx 83.3 \dot{m}$

Take note that these data points are the points of the optimum operating conditions (highest maximum net power output) for different micro-turbines and different concentrator diameters. When including all of the data points from the analysis, this linear relationship disappears underneath a scattering of data. The linear relationship is thus only valid for an optimised geometry at the optimum operating conditions of different micro-turbines. These results stayed the same when either a tube or rectangular channel receiver was used. Other studies have found that, for a rectangular channel, an aspect ratio of eight should be used for minimum entropy generation in the channel [20]. In this work, however, results show that an aspect ratio of eight is not necessarily the optimum aspect ratio for the receiver and recuperator channels in a system which should produce maximum net power output. This is because EGM was done for the whole system, instead of for components individually. Also, when plotting the optimum recuperator channel width, again a linear relationship was found.

The optimum recuperator length, $L_{\text {reg,opt }}$, mostly converged on its constraint, as was set in Equation (35). This is shown in Figure 12, where all the data points are shown. For a specific concentrator diameter, the optimum recuperator length increases as the mass flow rate increases until the constraint is reached. It is concluded that, for a specific concentrator diameter, a short recuperator is beneficial for a system with a relatively small mass flow rate, although a small mass flow rate would not establish the highest maximum net power output.

In Figure 13, the optimum hydraulic diameter of the recuperator channels is shown as a function of system mass flow rate. At small mass flow rates, the optimum hydraulic diameter increases as the system mass flow rate increases, until the recuperator length constraint is reached. For increasing mass flow rate, the optimum hydraulic diameter decreases until a minimum diameter is reached where the maximum pressure drop exists. The optimum hydraulic diameter increases slightly as the mass flow rate increases.

Figure 14 shows that there exists a linear relationship between the minimum internal and minimum external irreversibility rates for the system. Again, these data points are the points of optimum operating conditions for different micro-turbines and different concentrator diameters. Results show that the irreversibilities are spread throughout the system in such a way that the internal irreversibility rate is roughly three times the external irreversibility rate. This result can be approximated for all 
concentrators and micro-turbines with an optimum operating condition in this analysis with Equation (39),

$$
\left.-T_{0} \mid \dot{S}_{g e n}\right\rfloor_{\mathrm{int}} \approx C_{W}\left[\dot{m} c_{p 0}\left(T_{1}-T_{11}\right)-\dot{m} T_{0} c_{p 0} \ln \left(T_{1} / T_{11}\right)\right]_{e x t}
$$

where

$$
C_{W}=\dot{I}_{\mathrm{int}, \min } / \dot{I}_{e x t, \min } \approx 3
$$

Figure 15 shows that for a specific concentrator diameter, $C_{W}$ increases as the system mass flow rate increases. The rate of increase decreases as the concentrator diameter increases. Figure 15 shows that $2.4 \leq C_{W} \leq 4$. Other data points which are not at an optimum operating point, or close to one, do not fall in this range.

\section{CONCLUSION}

The second law of thermodynamics is a valuable contribution to the optimisation of solar thermal power systems. The geometry of components in a system should be optimised by minimising the total rate of entropy generation in the system in such a way that the system produces maximum net power output. The geometry of the receiver and recuperator in a small-scale open and direct recuperative solar thermal Brayton cycle was optimised in this paper, in such a way that the system produces maximum net power output. The second law of thermodynamics and entropy generation minimisation were applied and the dynamic trajectory optimisation method was used. The maximum thermal efficiency of the system was found to be a function of the solar concentrator diameter and choice of micro-turbine. No major differences could be found in the maximum net power output between cavity receivers constructed with a rectangular channel and a round tube respectively. It was found that a large solar cavity receiver aperture or a small rectangular channel aspect ratio, but not necessarily both, is most beneficial. Also, the receiver tube diameter should be relatively large. Other studies have found that, for a rectangular channel, an aspect ratio of eight should be used for minimum entropy generation. In this work, results show that an aspect ratio of eight is not necessarily the optimum aspect ratio for the receiver and recuperator channels in a system which should produce maximum net power output. For highest maximum net power output, the optimum recuperator channel aspect ratio for the counterflow-plated recuperator with a constant recuperator height, was found to be a linear function of the system mass flow rate. For a specific concentrator diameter and micro-turbine, a short recuperator is beneficial if the system operates at relatively small mass flow rates. Results showed that the irreversibilities were spread throughout the system in such a way that the internal irreversibility rate was almost three times the external irreversibility rate for all optimum system geometries and operating conditions. Further studies would entail the construction and testing of various experimental models and a comparison of the results with the current analytical and numerical approach. 
NOMENCLATURE

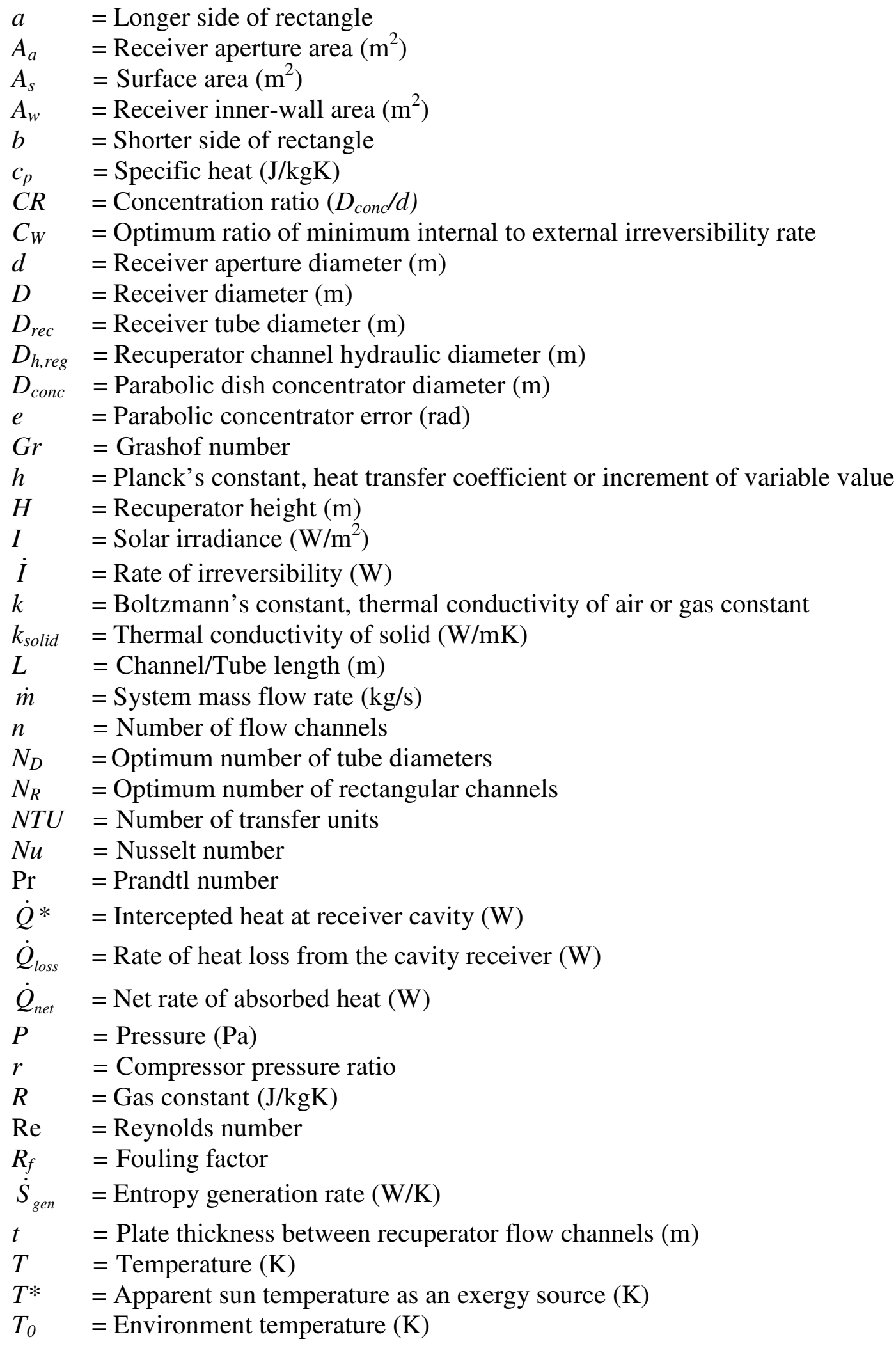




$$
\begin{array}{ll}
v & =\text { Frequency } \\
V & =\text { Velocity }(\mathrm{m} / \mathrm{s}) \\
\dot{W} & =\text { Power }(\mathrm{W}) \\
\dot{W}_{n e t} & =\text { Net power output of system }(\mathrm{W}) \\
X & =\text { Variable optimisation vector } \\
y & =\text { Numerical approximation constant } \\
Z & =\text { Height }(\mathrm{m}) \\
\beta & =\text { Inclination of receiver } \\
\Delta & =\text { Change in } \\
\varepsilon & =\text { Effectiveness (in the } \varepsilon-N T U \text { method) } \\
\psi r i m & =\text { Concentrator rim angle } \\
\lambda & =\text { Wave length } \\
\mu & =\text { Dynamic viscosity } \\
\eta & =\text { Efficiency }
\end{array}
$$

\section{Subscripts}

$\begin{array}{ll}0 & =\text { Environment/Loss } \\ c & =\text { Compressor } \\ \text { conc } & =\text { Concentrator } \\ \text { conv } & =\text { Convection } \\ \text { ext } & =\text { External } \\ h & =\text { Hydraulic } \\ \text { int } & =\text { Internal } \\ \text { max } & =\text { Maximum } \\ \text { min } & =\text { Minimum } \\ \text { opt } & =\text { Optimum } \\ \text { rad } & =\text { Radiation } \\ \text { rec } & =\text { Receiver } \\ r e g & =\text { Recuperator } \\ s & =\text { Surface } \\ t & =\text { Turbine } \\ \text { th } & =\text { Thermal } \\ w & =\text { Wall }\end{array}$

\section{REFERENCES}

1. Chen L, Zhang W, Sun F. Power, efficiency, entropy-generation rate and ecological optimization for a class of generalized irreversible universal heat-engine cycles. Applied Energy 2007; 84: 512-525.

2. Mills D. Advances in solar thermal electricity technology. Solar Energy 2004; 76: 1931. 
3. Shah RK. Compact Heat Exchangers for Microturbines. Micro Gas Turbines 2005; 2-1 - 2-18. Educational Notes RTO-EN-AVT-131, Paper 2. Neuilly-sur-Seine, France: RTO. Available at: http://www.rto.nato.int/abstracts.asp [Accessed 28 April 2010].

4. Bejan A. Entropy Generation through Heat and Fluid Flow. Colorado: John Wiley \& Sons, Inc, 1982.

5. Kreith F, Kreider JF. Principles of Solar Engineering. Colorado: Hemisphere Publishing Corporation, 1978.

6. Bejan A, Tsatsaronis G, Moran M. Thermal Design and Optimization. New York: John Wiley \& Sons, Inc, 1996.

7. Oğulata RT, Doba F, Yilmaz T. Irreversibility analysis of cross flow heat exchangers. Energy Conversion \& Management 2000; 41 (15): 1585-1599.

8. Yilmaz M, Sara ON, Karsli S. Performance evaluation criteria for heat exchangers based on second law analysis. Exergy, an International Journal 2001; 1 (4): 278294.

9. Bejan A. Advanced Engineering Thermodynamics. $2^{\text {nd }}$ ed. Durham: John Wiley \& Sons, Inc, 1997.

10. Petela R. Engineering Thermodynamics of Thermal Radiation. New York: McGrawHill, 2010.

11. Joshi AS, Dincer I, Reddy BV. Development of new solar exergy maps. International Journal of Energy Research 2009; 33: 709-718.

12. Agudelo A, Cortés C. Thermal radiation and the second law. Energy 2010; 35 (2): 679-691.

13. Stine BS, Harrigan RW. Solar Energy Fundamentals and Design. New York: John Wiley \& Sons, Inc, 1985.

14. Shuai Y, Xia X, Tan H. Radiation performance of dish solar concentrator/cavity receiver systems. Solar Energy 2008; 82: 13-21.

15. Prakash M, Kedare SB, Nayak JK. Investigations on heat losses from a solar cavity receiver. Solar Energy 2009; 83: 157-170.

16. Sendhil Kumar N, Reddy KS. Comparison of receivers for solar dish collector system. Energy Conversion and Management 2008; 49: 812-819.

17. Sendhil Kumar N, Reddy KS. Numerical investigation of natural convection heat loss in modified cavity receiver for fuzzy focal solar dish concentrator. Solar Energy 2007; 81: 846-855.

18. Reddy KS, Sendhil Kumar N. Combined laminar natural convection and surface radiation heat transfer in a modified cavity receiver of solar parabolic dish. International Journal of Thermal Sciences 2008; 47: 647-1657.

19. Reddy KS, Sendhil Kumar N. An improved model for natural convection heat loss from modified cavity receiver of solar dish concentrator. Solar Energy 2009; 83: 1884-1892.

20. Ratts BE, Raut AG. Entropy generation minimization of fully developed internal flow with constant heat flux. Journal of Heat Transfer 2004; 126 (4): 656-659.

21. Zimparov VD, Da Silva AK, Bejan A. Thermodynamic optimization of tree-shaped flow geometries with constant channel wall temperature. International Journal of Heat and Mass Transfer 2006; 49: 4839-4849.

22. Zimparov VD, Da Silva AK, Bejan A. Constructal tree-shaped parallel flow heat exchangers. International Journal of Heat and Mass Transfer 2006; 49: 4558-4566. 
23. Zimparov VD, Da Silva AK, Bejan A. Thermodynamic optimization of tree-shaped flow geometries. International Journal of Heat and Mass Transfer 2006; 49: 16191630.

24. Sarangi S, Chowdhury K. On the generation of entropy in a counterflow heat exchanger. Cryogenics 1982; 22 (2): 63-65.

25. Cornelissen RL, Hirs GG. Exergetic optimization of a heat exchanger. Energy Conversion and Management 1997; 1 (15-17): 1567-1576.

26. Zimparov V. Extended performance evaluation criteria for enhanced heat transfer surfaces: heat transfer through ducts with constant heat flux. International Journal of Heat and Mass Transfer 2001; 44 (1): 169-180.

27. Hesselgreaves JE. Rationalisation of second law analysis of heat exchangers. International Journal of Heat and Mass Transfer 2000; 43 (22): 4189-4204.

28. Ordóñez JC, Bejan A. Entropy generation minimization in parallel-plates counterflow heat exchangers. International Journal of Energy Research 2000; 24: 843-864.

29. Ishikawa $\mathrm{H}$, Hobson PA. Optimisation of heat exchanger design in a thermoacoustic engine using a second law analysis. International Communications in Heat and Mass Transfer 1996; 23 (3): 325-334.

30. Shiba T, Bejan A. Thermodynamic optimization of geometric structure in the counterflow heat exchanger for an environmental control system. Energy 2001; 26: 493-511.

31. Lerou PPPM, Veenstra TT, Burger JF, Ter Brake HJM, Rogalla H. Optimization of counterflow heat exchanger geometry through minimization of entropy generation. Cryogenics 2005; 45: 659-669.

32. Khennich M, Galanis N. Thermodynamic analysis and optimization of power cycles using a finite low-temperature heat source. International Journal of Energy Research 2011; DOI: 10.1002/er.1839.

33. Narendra S, Kaushik SC, Misra RD. Exergetic analysis of a solar thermal power system. Renewable Energy 2000; 19: 135-143.

34. Jubeh NM. Exergy analysis and second law efficiency of a regenerative Brayton cycle with isothermal heat addition. Entropy 2005; 7 (3): 172-187.

35. Gomez A, Azzaro-Pantel C, Domenech S, Pibouleau L, Latge' C, Haubensack D, Dumaz P. Exergy analysis for Generation IV nuclear plant optimization. International Journal of Energy Research 2011; 34: 609-625.

36. Hovsapian R, Vargas JVC, Ordonez JC, Krothapalli A, Parise JAR, Berndsen JC. Thermodynamic optimization of a solar system for cogeneration of water heating and absorption cooling. International Journal of Energy Research 2008; 32: 12101227.

37. Öztürk A, Şenel A, Onbaşığlu SU. Thermodynamic optimization of combined cycles. International Journal of Energy Research 2005; 29: 657-670.

38. Alebrahim A, Bejan A. Thermodynamic optimization of heat-transfer equipment configuration in an environmental control system. International Journal of Energy Research 2001; 25: 11277-1150.

39. Bejan A. Method of entropy generation minimization, or modeling and optimization based on combined heat transfer and thermodynamics. Revue Générale de Thermique 1996; 35: 637-646. 
40. DME, Department of Minerals and Energy, Republic of South Africa, 2010. Solar Energy. [online]. Available at: http://www.dme.gov.za/energy/renew_solar.stm [Accessed 20 July 2010].

41. Burden RL, Faires JD. Numerical Analysis. $8^{\text {th }}$ ed. Youngston State University: Thomson Brooks/Cole, 2005.

42. Gnielinski V. New equations for heat and mass transfer in turbulent pipe and channel flow. International Chemical Engineering 1976; 16: 359-368.

43. Petukhov BS. Heat transfer and friction in turbulent pipe flow with variable physical properties. Advances in Heat Transfer 1970; 6.

44. Çengel YA. Heat and Mass Transfer. $3^{\text {rd }}$ ed. Nevada, Reno: McGraw-Hill, 2006.

45. Snyman JA. Practical Mathematical Optimization. Pretoria: University of Pretoria, 2009.

46. Garrett, 2009. Garrett by Honeywell: Turbochargers, Intercoolers, Upgrades, Wastegates, Blow-Off Valves, Turbo-Tutorials. Available at: http://www.TurboByGarrett.com [Accessed 26 April 2010].

47. Dittus FW, Boelter LMK. University of California Publications on Engineering 1930; 2: 433.

48. Snyman JA. The LFOPC leap-frog algorithm for constrained optimization. Computers and Mathematics with Applications 2000; 40: 1085-1096. 


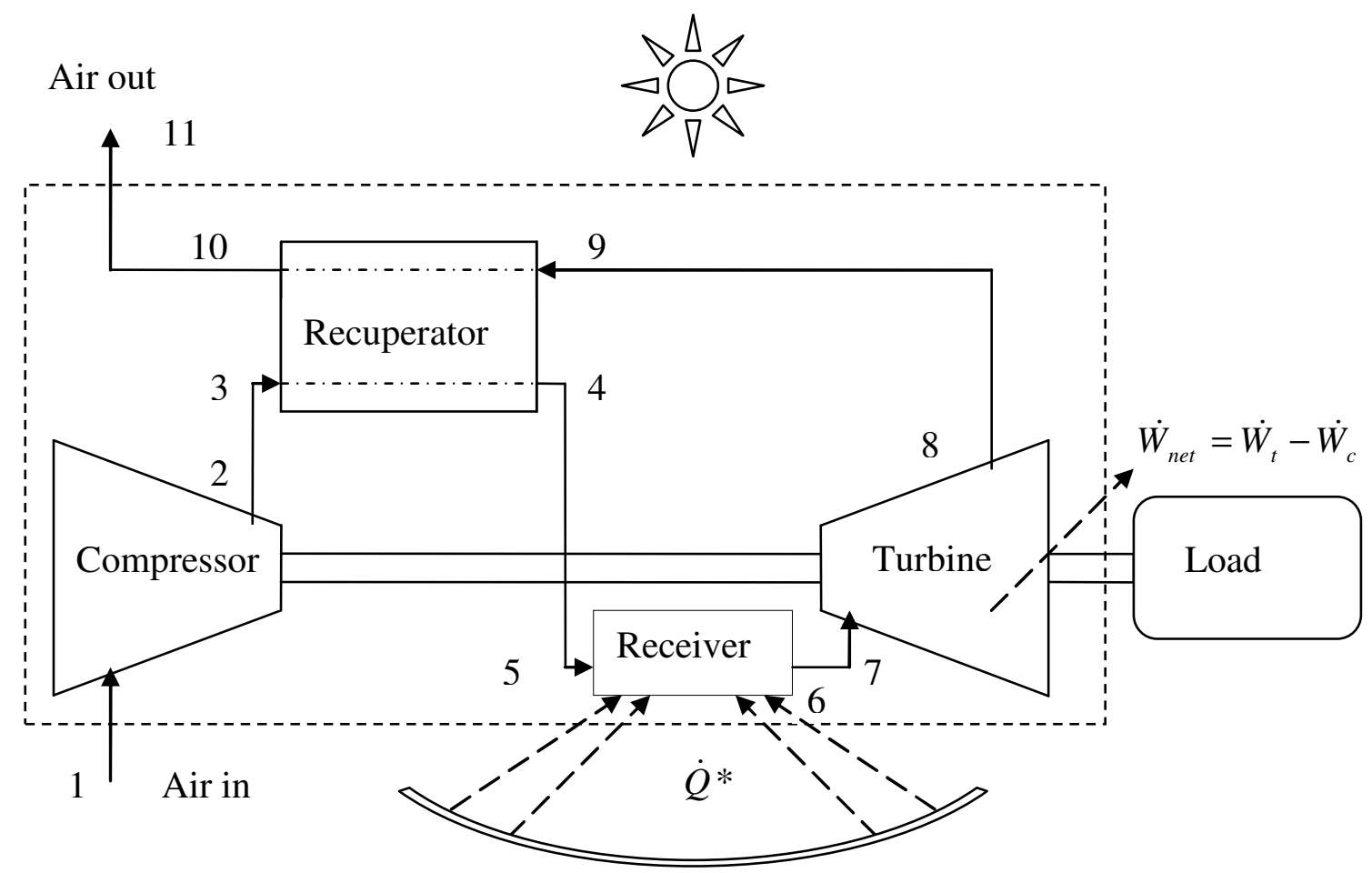

Figure 1 


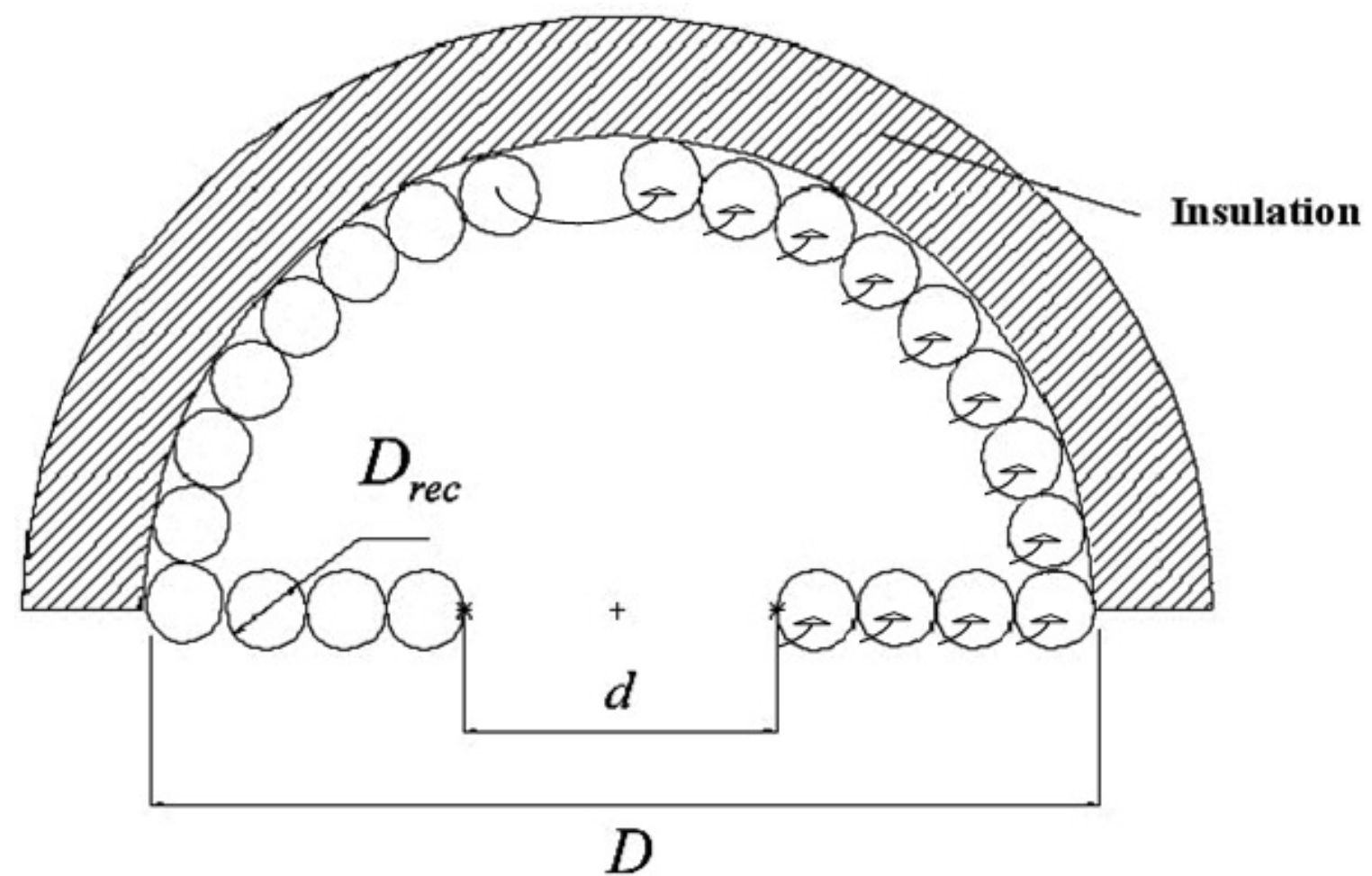

Figure $2 \mathrm{a}$ 


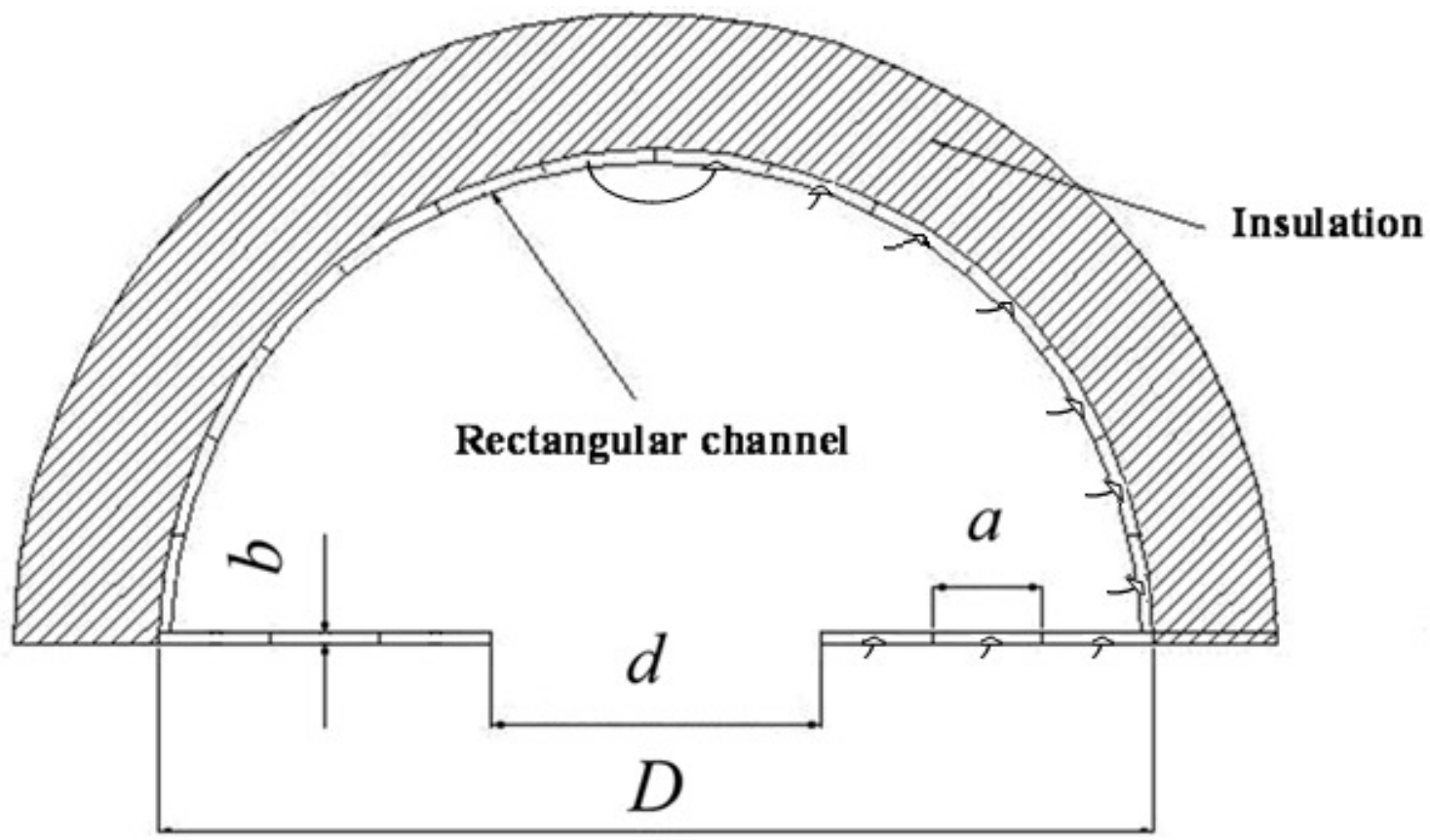

Figure $2 b$ 


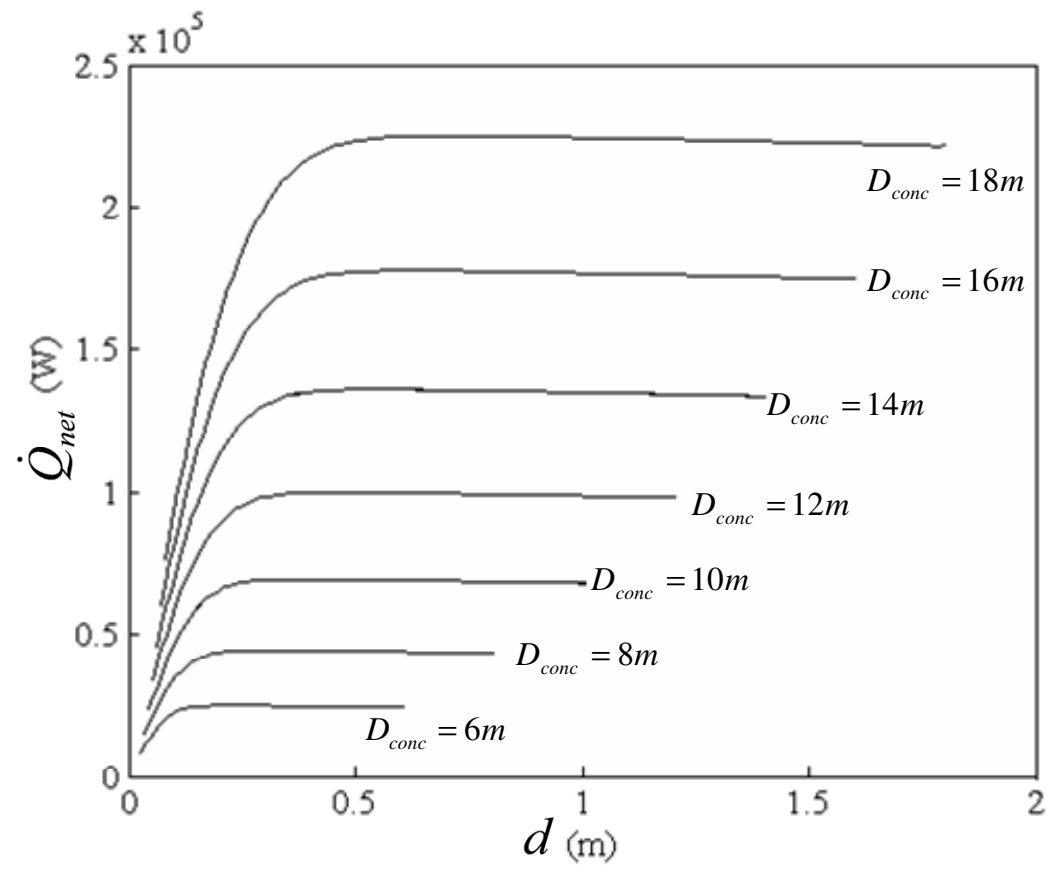

Figure 3 


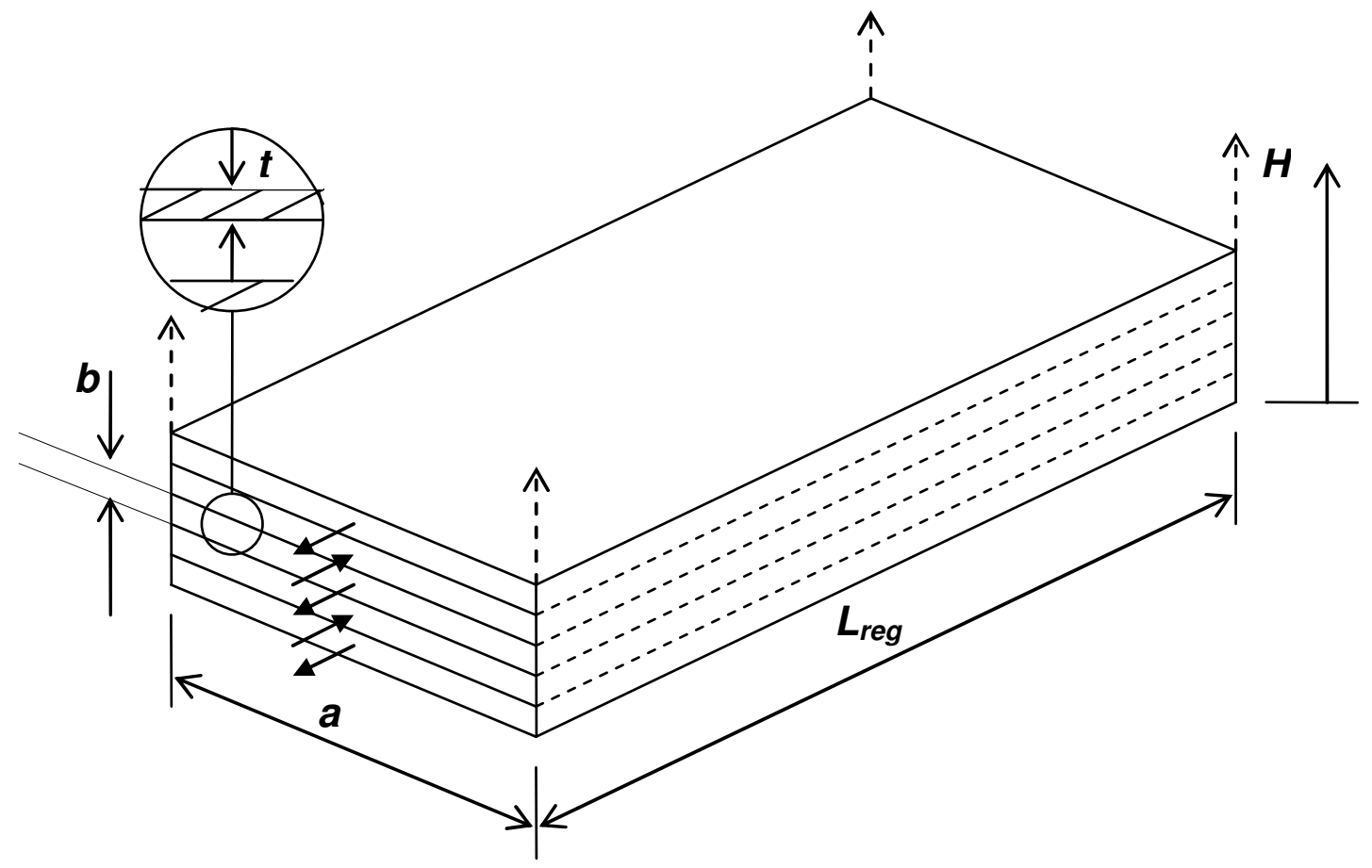

Figure 4 


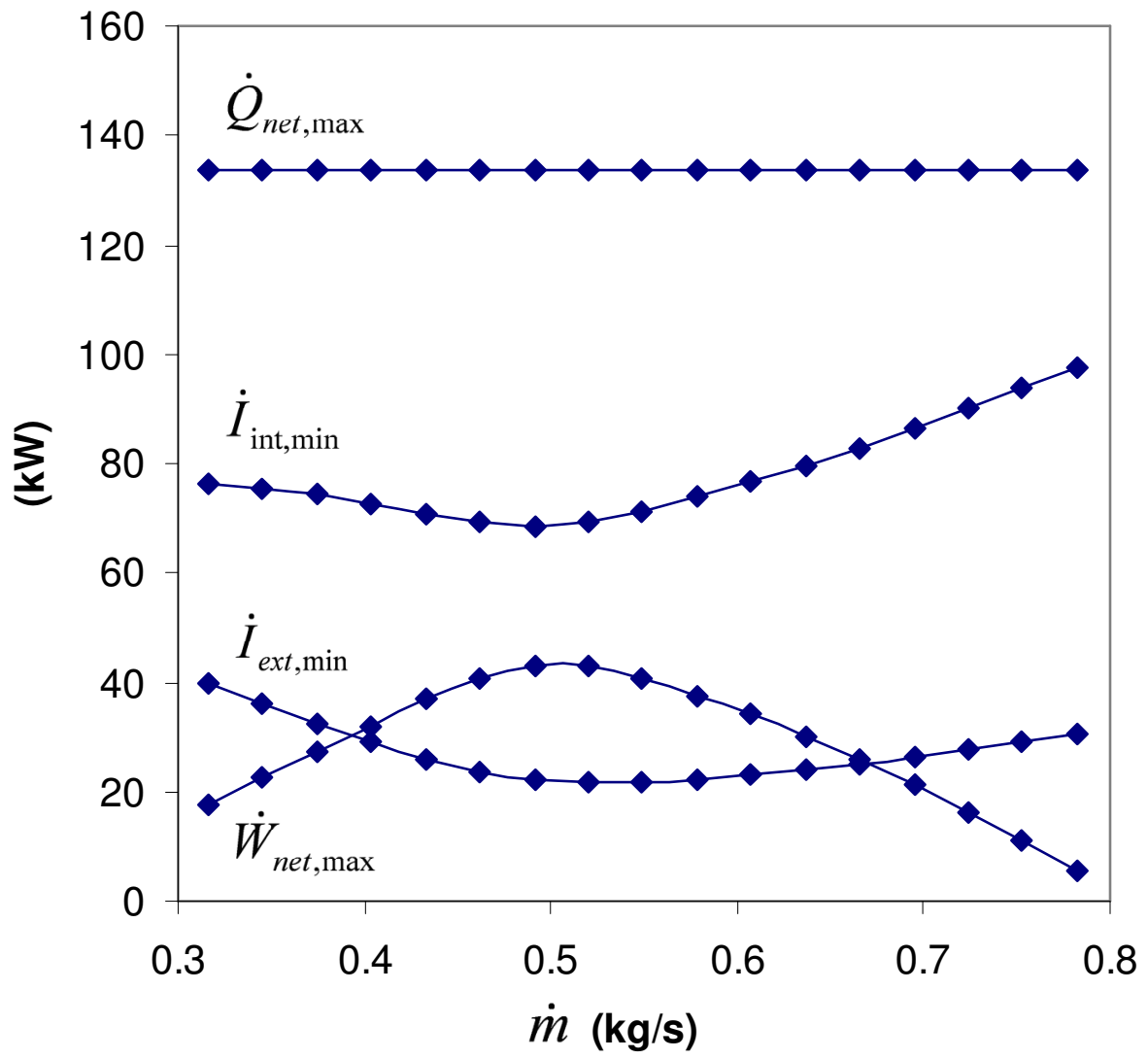

Figure 5 


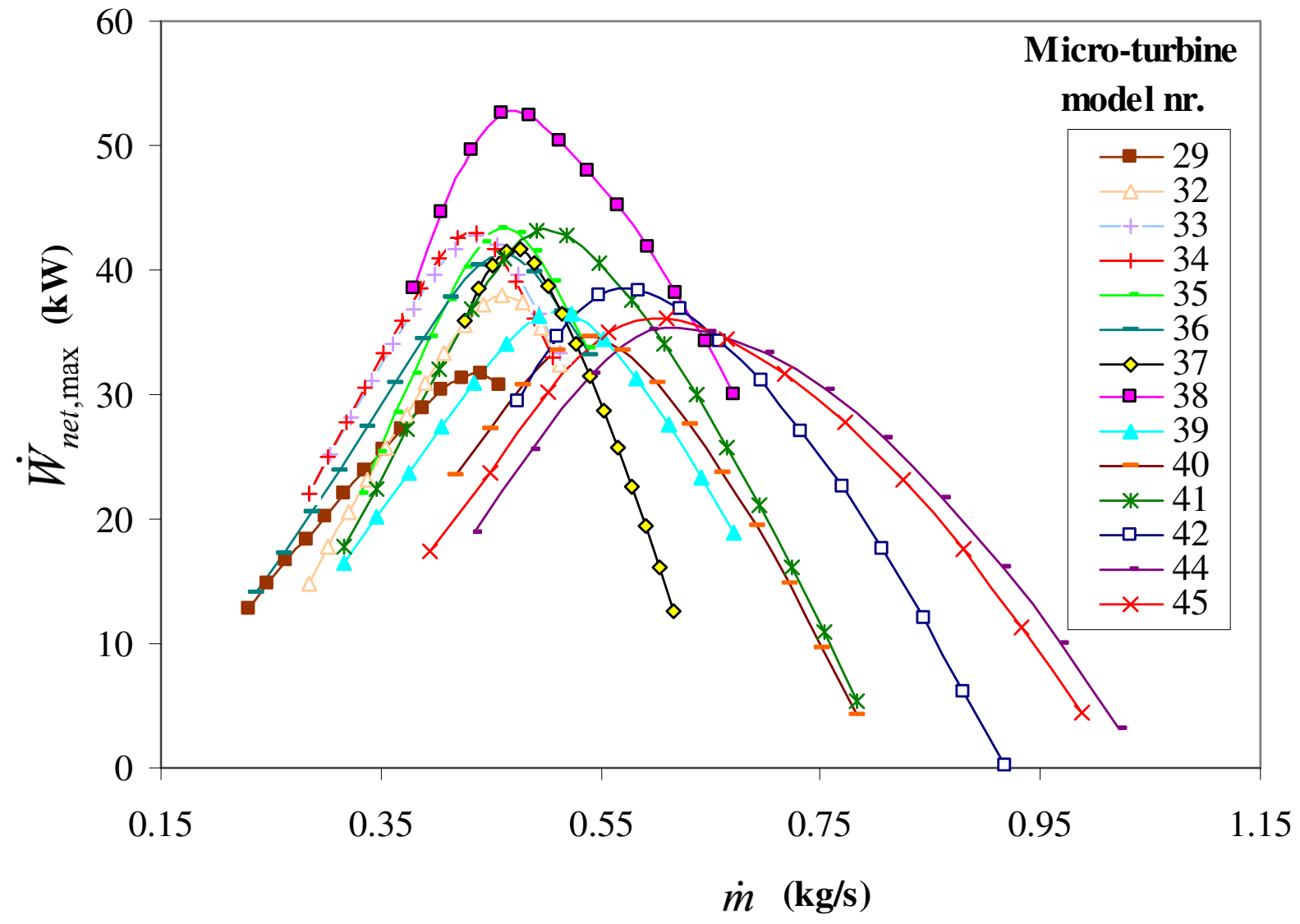

Figure 6 


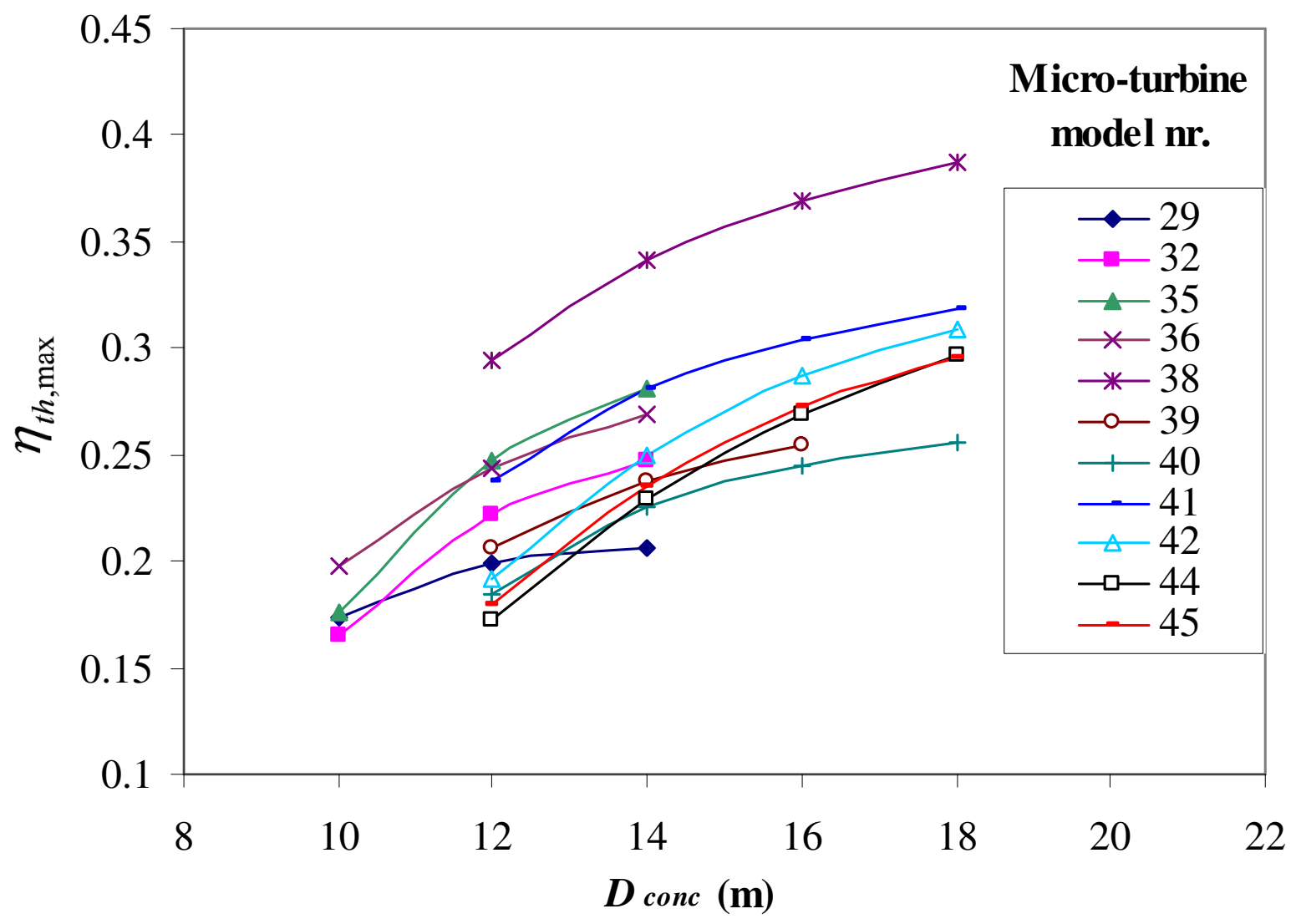

Figure 7 


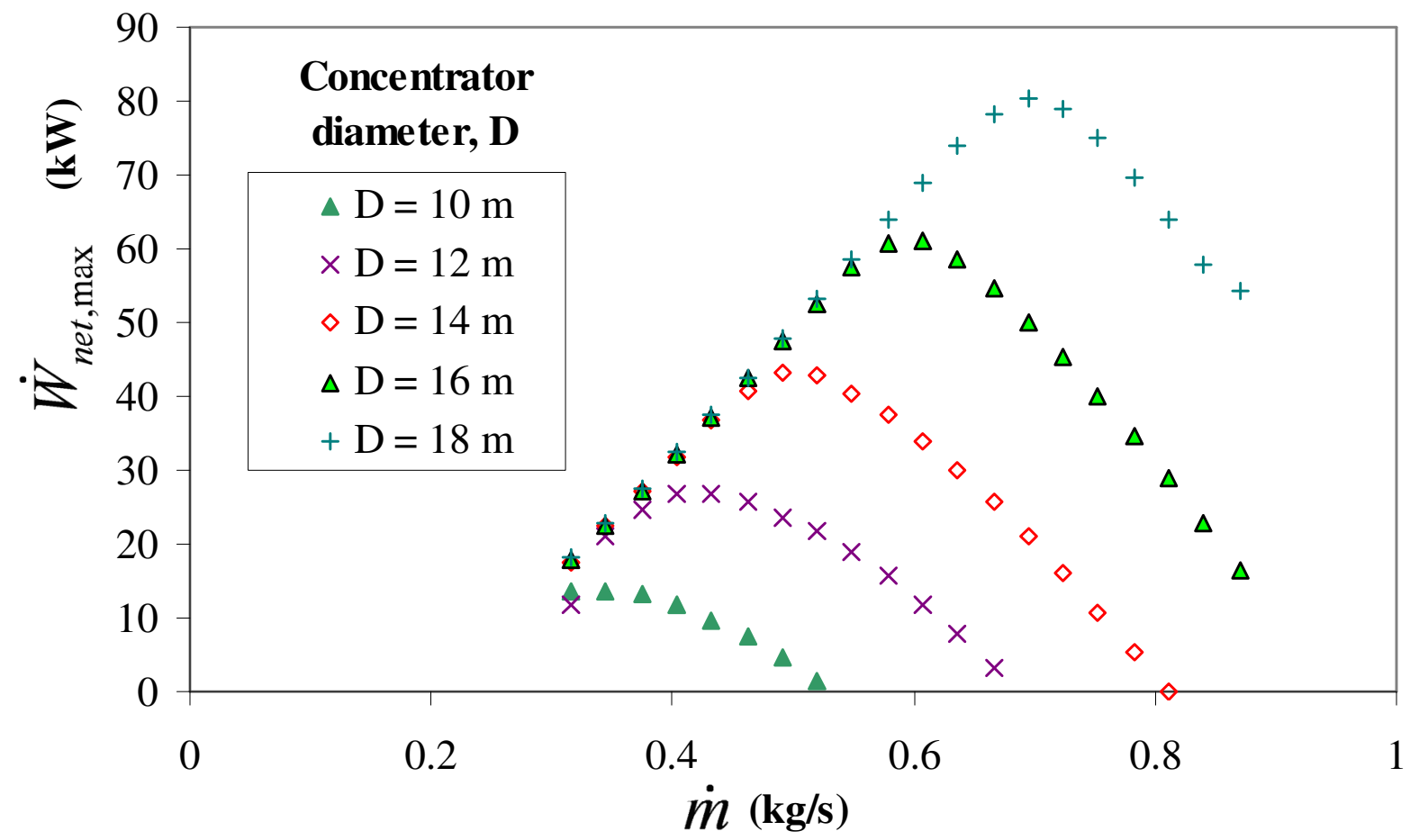

Figure 8 


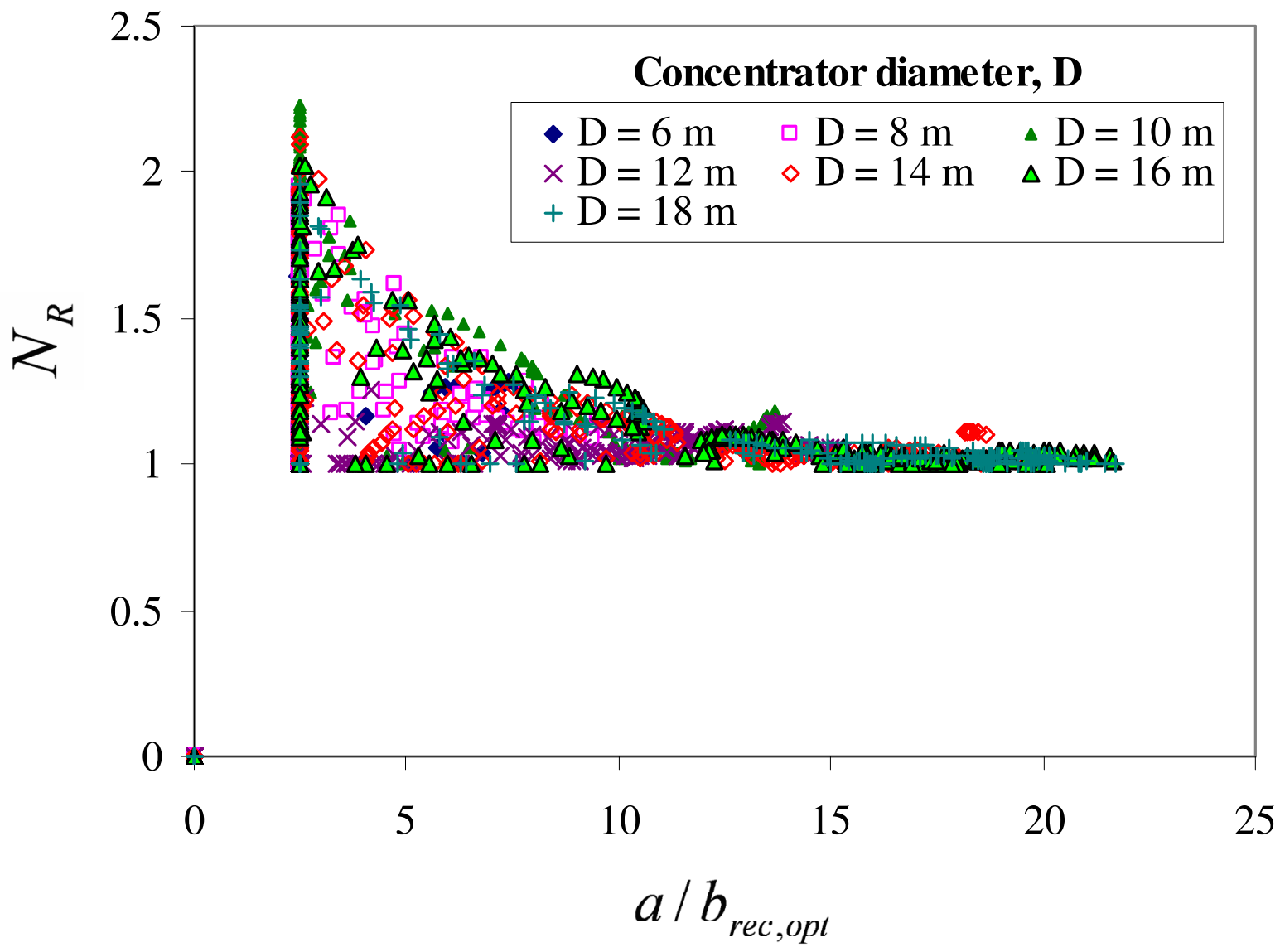

Figure 9 


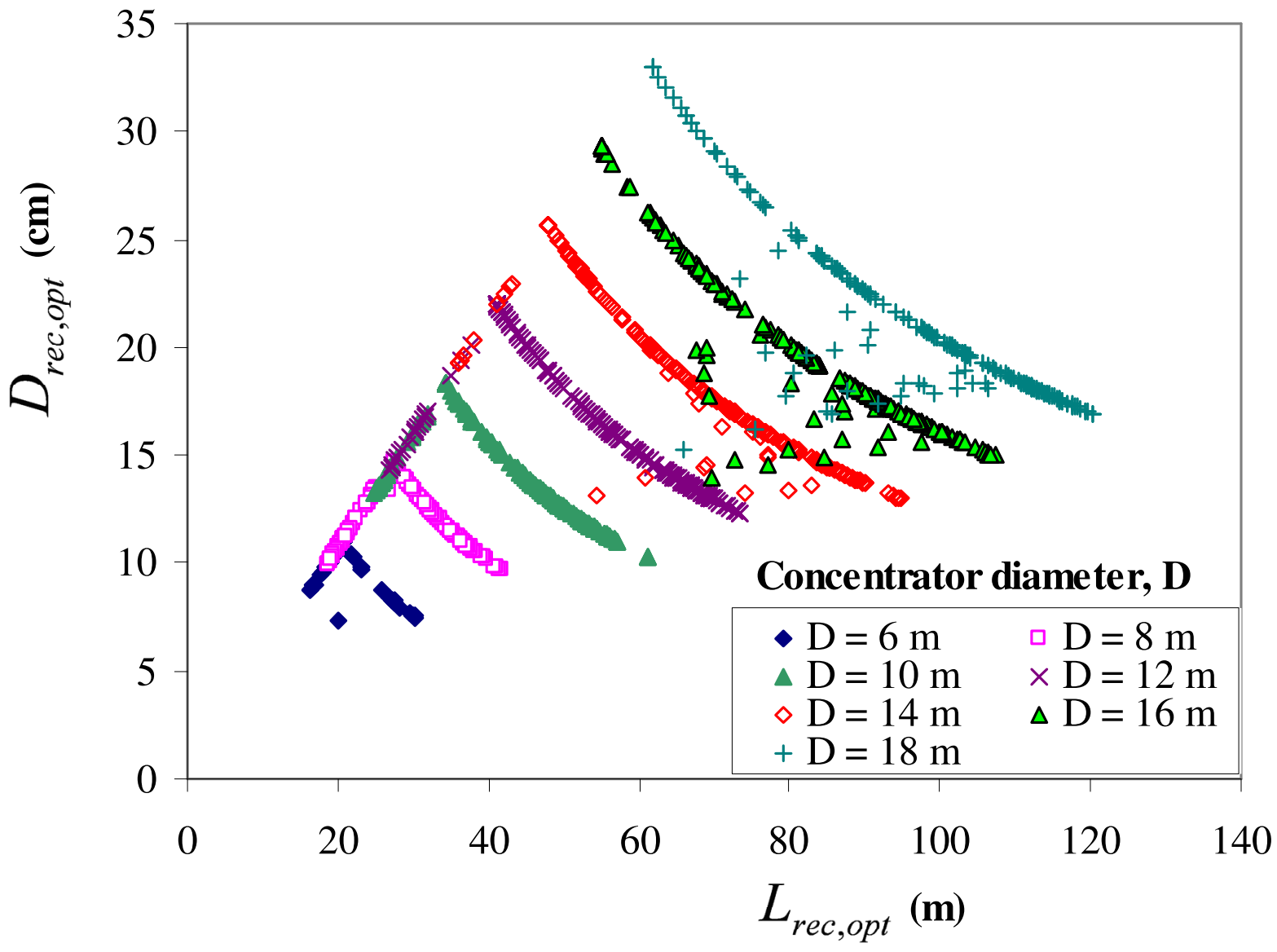

Figure 10 


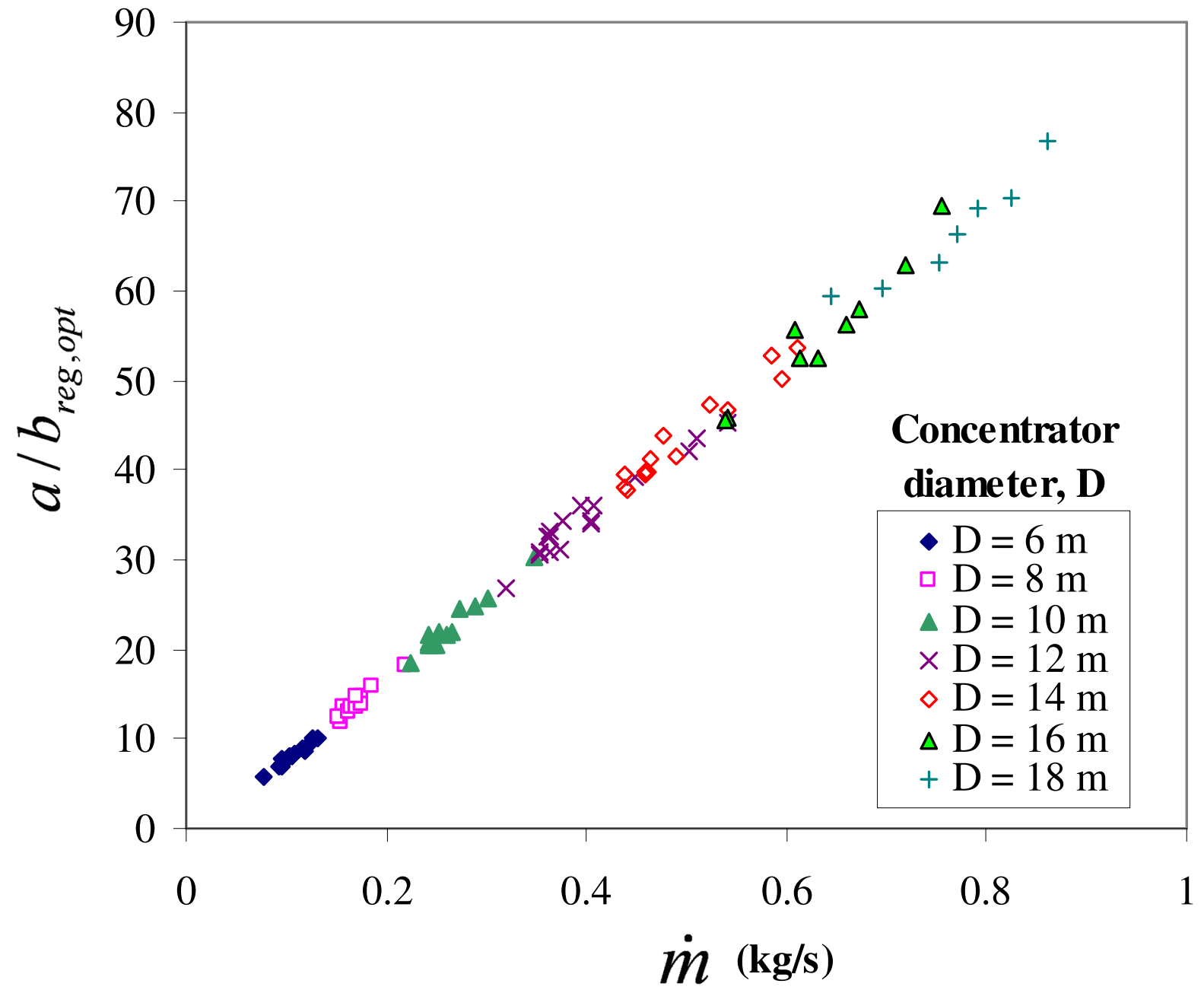

Figure 11 


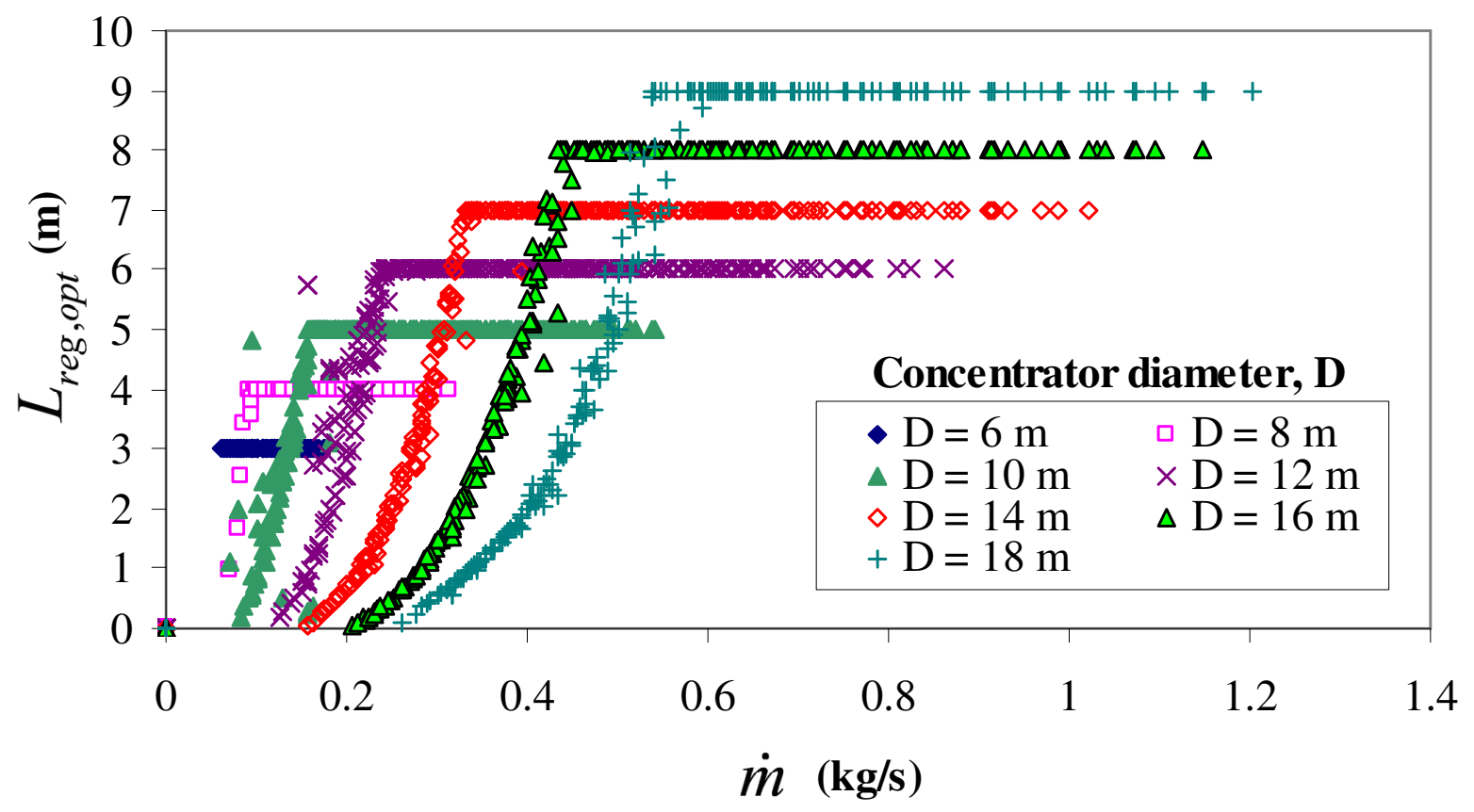

Figure 12 


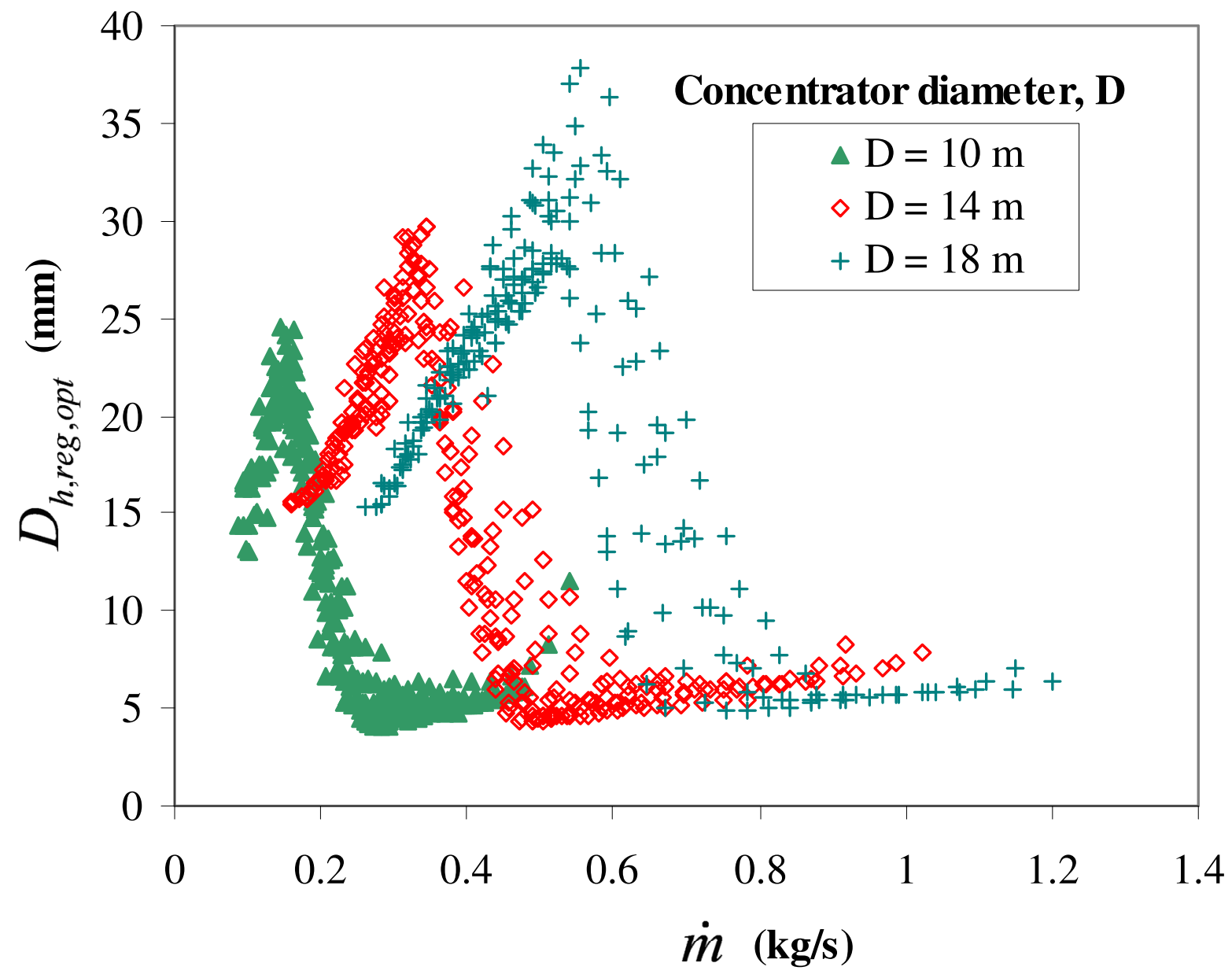

Figure 13 


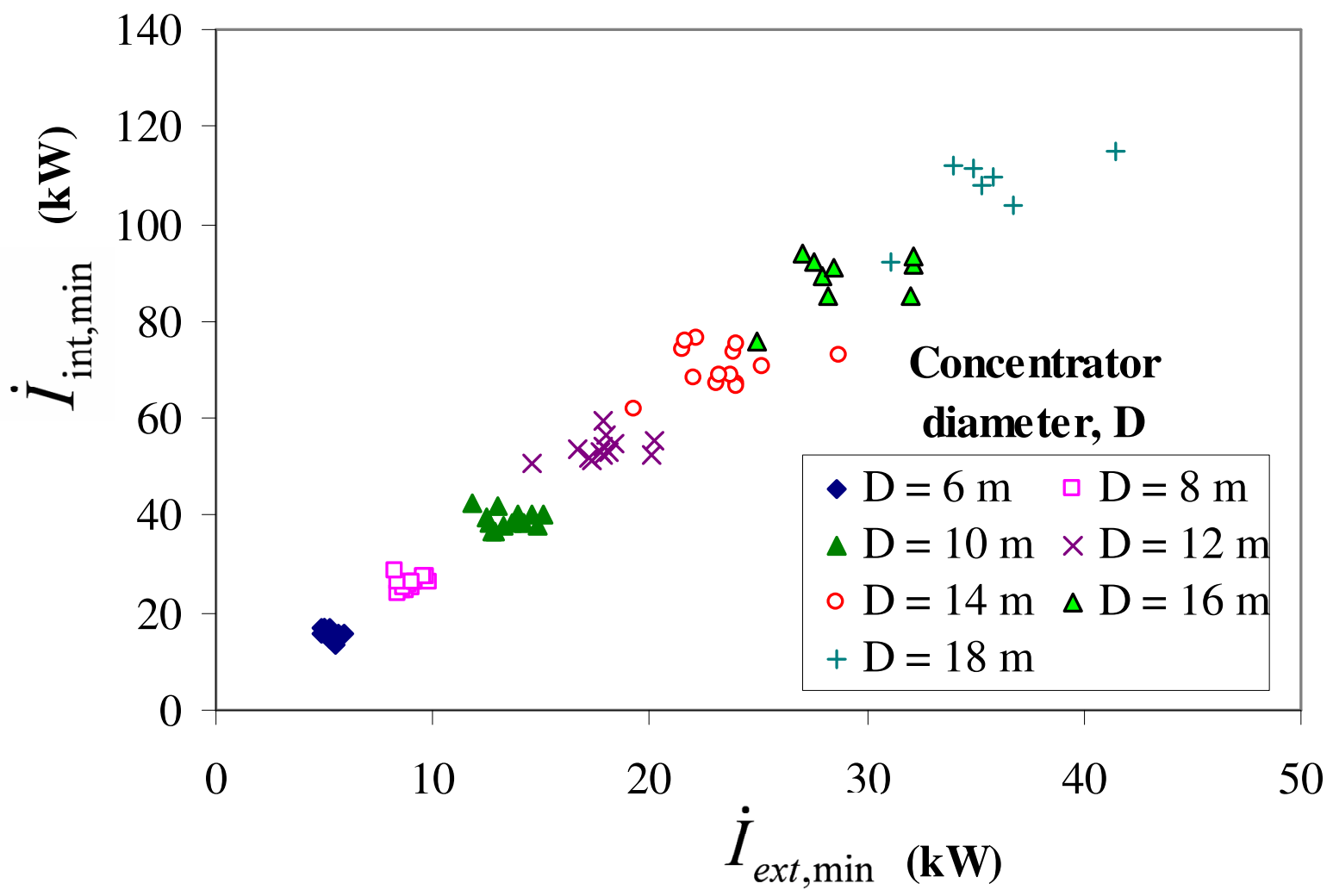

Figure 14 


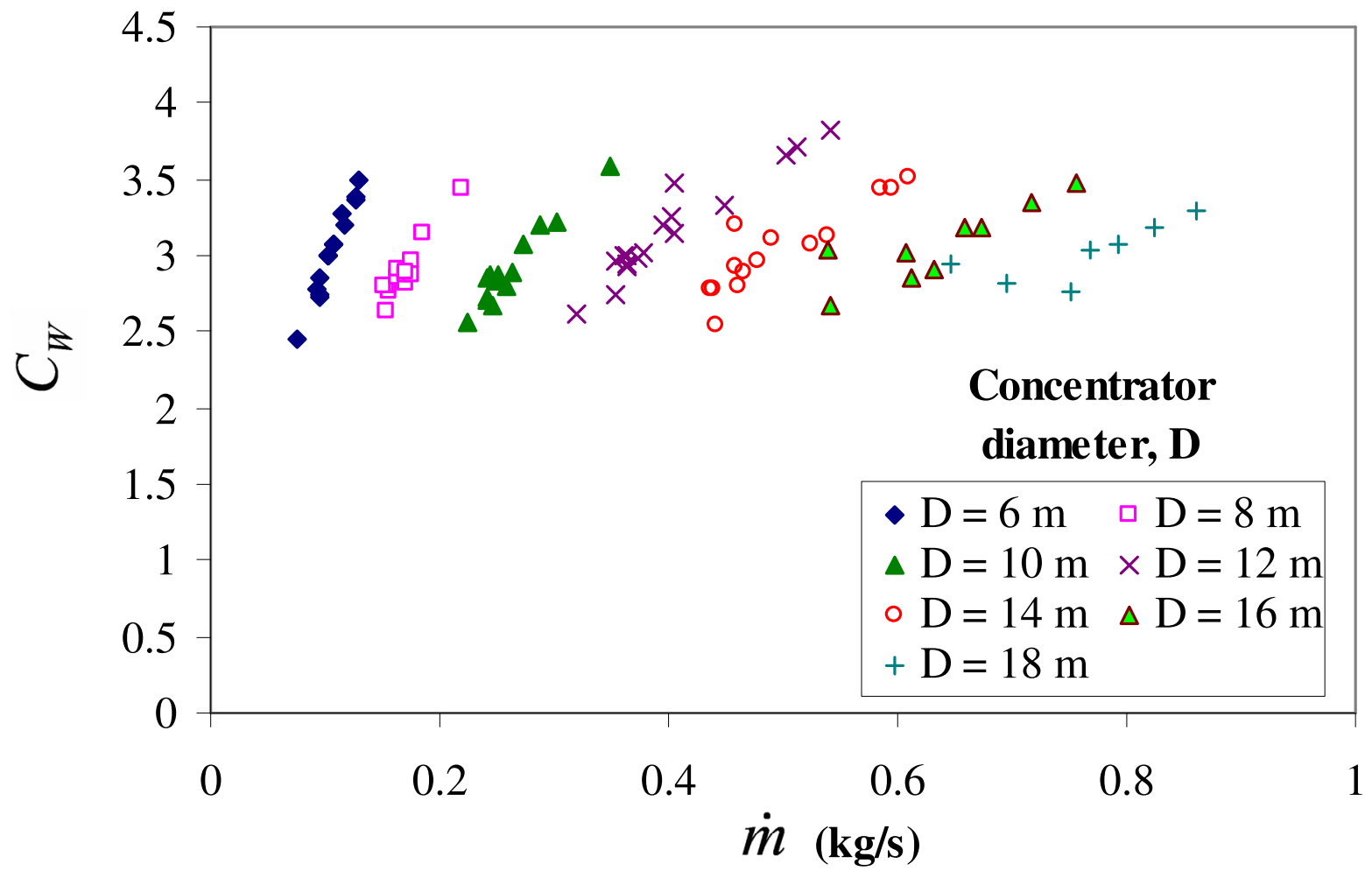

Figure 15 


\section{FIGURE CAPTIONS}

Figure 1. The open and direct solar thermal Brayton cycle with recuperator.

Figure 2a. Section view of the cavity receiver showing the cut through the circular tube, which is wounded to construct the receiver walls.

Figure $2 \mathrm{~b}$. Section view of the cavity receiver showing the cut through the rectangular channel, which is wounded to construct the receiver walls.

Figure 3. Relation between the net absorbed solar heat rate and the receiver aperture diameter for different concentrator diameters.

Figure 4. A segment of the counterflow-plated recuperator showing the channel geometry.

Figure 5. Maximum net power output, minimum irreversibility rates and maximum net absorbed heat rate as a function of mass flow rate for $D_{\text {conc }}=14 \mathrm{~m}$ and Micro-turbine 41 .

Figure 6. Maximum net power output for different micro-turbines in their operating ranges of maximum compressor efficiency for a concentrator with a diameter of $14 \mathrm{~m}$.

Figure 7. Highest maximum thermal efficiencies of the optimized systems as a function of concentrator diameter and micro-turbine choice.

Figure 8. Roofline for the maximum net power output for Micro-turbine 41 with different concentrator diameters.

Figure 9. Optimum number of rectangular channels between receiver edge and receiver aperture as a function of optimum receiver channel aspect ratio for all data points.

Figure 10. Relationship between the optimum receiver tube diameter and optimum receiver tube length.

Figure 11. Optimum aspect ratio of the recuperator channels for highest maximum net power output of various micro-turbines as a function of system mass flow rate.

Figure 12. Optimum recuperator length as a function of system mass flow rate for all micro-turbines and concentrator diameters used in the analysis.

Figure 13. Optimum hydraulic diameter of recuperator channels as a function of system mass flow rate for $D_{c o n c}=10,14$ and $18 \mathrm{~m}$.

Figure 14. Minimum internal system irreversibility rate as a function of minimum external system irreversibility rate of the systems with highest maximum net power output. 
Figure 15. Ratio of internal to external irreversibility rate of the systems with highest maximum net power output as a function of mass flow rate and concentrator diameter. 